Journal of Engineering Sciences, Assiut University, Vol. 35, No.1, pp. January 2007

\title{
THE MODERN ARCHITECTURAL ENVIRONMENT AND ITS EFFECTS ON THE TOWN PANORAMA VIEW (CASE STUDY ON THE SANA'A CITY OUTSIDE THE OLD SANA'A TOWN WALL )
}

\author{
Dr. Mohammed M. Al Olofi \\ Assistant Professor Dept. of Architecture College of Engineering University of \\ Sana'a
}

(Received December13, 2006 Accepted December24, 2006)

Environment to those interesting community, scholars and prior to that architects' engineers could be classified into three parts. The natural environment, the social and of course the industrial. All that we mean in this study is the last. We mean by that the group entire of components related to man's activity, and man surroundings as a whole. This would contain the buildings, parks, the squares, the open recreational centers, roads, highways, bridges and industries etc. In additional to that comes the factor of the environmental effects. Hence the modern architectural environmental in tremendous many towns have been affected by a lot of the factors that caused towns to lose the optimal ideal properties, despite all efforts and attempts exerted in aims of enhancements and developing.

This could be due to several reasons. The significant reason is the focusing ,mainly on the solely abstract economical prospective dimension without taking under consideration the other important factors. .Thus consequently and throughout time the reflect of that had worked to affect nature of the architectural environment as a whole. An effect of that also is negatively affects man's livelihood, guanine needs and related convenience. For instance towns were and still the favorite rendezvous centers for people to meet in, to arrange their various interests. Hence within towns there took place the different man's activities such the cultural, the political and the commercial exchanges, a thing objectively expresses the real wholeness of the urban life activities.

Whereas in fact any town could never ever be just seen and deemed as a consistent of just several number of buildings, businesses neighboring each other without taking under serious consideration the fact for the material constructional architectural components besides the behaviors of the co workers on.(1) Another $r$ factor is that the sound smoothness eye can not realize at seeing beauty serenity in absence of the intact sound planning art - craft and esthetic architecture besides the safety and the structural erecting and architectural environment which influences the users as a whole feeling of impressiveness such as love and terror, desire and pleasure.

Hence the most important constructional architectural environment in favor of Sana'a city is the absence of sound planning that could smoothly cope with and be in a harmony with the modern development whether that in the eco social dimensions or in the non full exploitation of the optimal chances of the private 
sector participation or due to the non exploitation of the local, Arab or foreign investments in concern..

These factors besides several others had effected nature of the architectural environment on Sana'a city. It affected the general view of Sana'a city, similar effects are on its inhabitants and even on its visitors. This research rises as a responsive for the discussion effects of the architectural environment prospects, on its inhabitants, The research at the same time tackles the periodically intervals transitions in history witnessed by Sana'a, together with the related range of the of that responses on the city and on its people In addition tackles the significance of the architectural environment, the functions related that determine the architectural environment and the development and renaissance of architecture movements, their effects and results on cities promote and enhancement as a whole and in particular on Sana'a city The research concludes to a group of outcomes associated by comments and recommendations

\section{البيئة المعمارية الحديثة وأثزها على مظهر المدينة

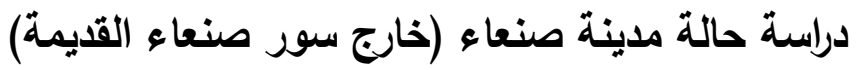

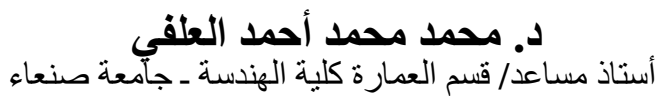

(Mohammad Al-olafy Tonje@Yahou.com)

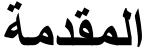

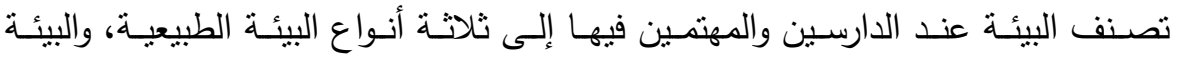

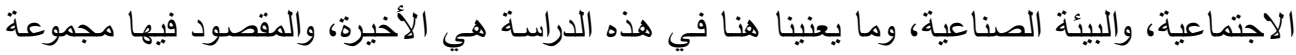

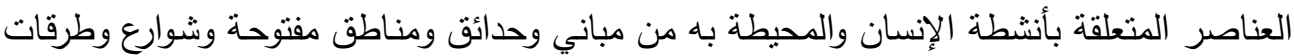

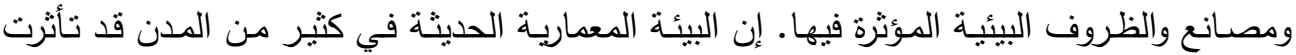

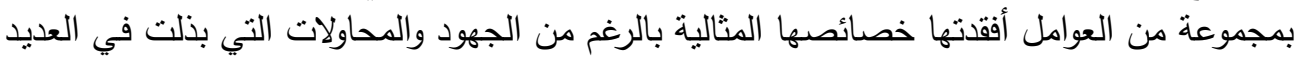

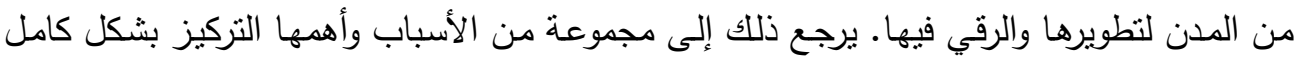

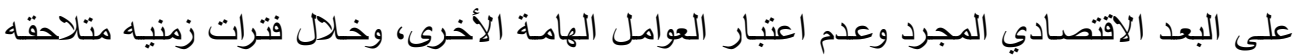

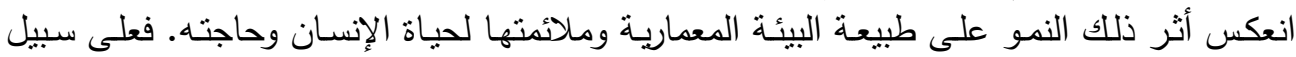

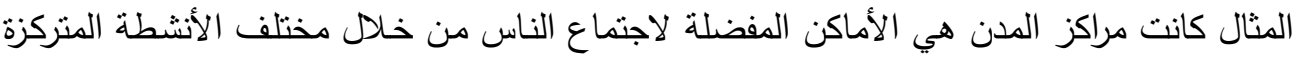

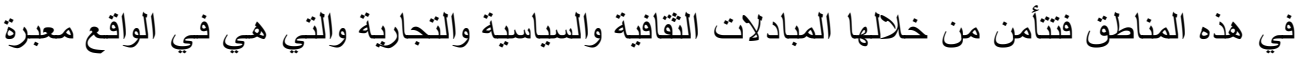
عن مجمل مناشط الحياة في المدينة. ومدينة صنعاء مرت بمراحل عدة من النمو والنطور فهي إحدى أقدم مدن العالم حيث سميت مدينة

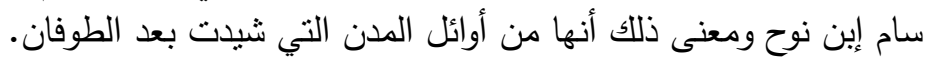

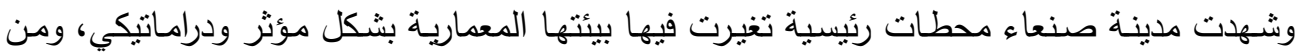

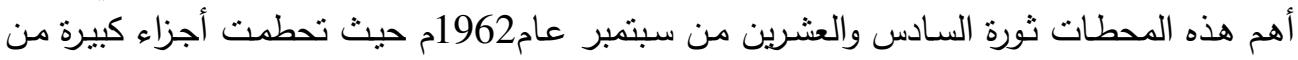

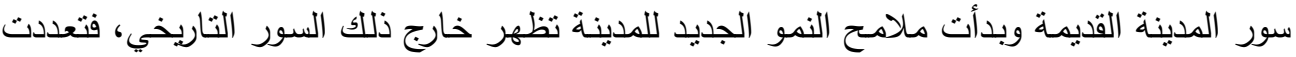

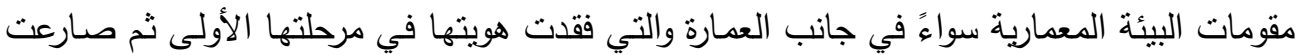

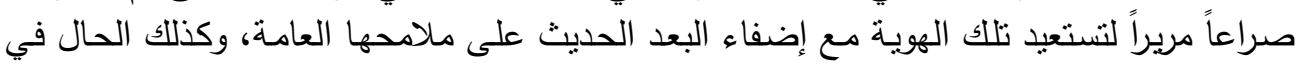


بقية مكوناتها من شوارع وساحات وحدائق وأماكن مفتوحة إلا أن المدينـة برغم المخططات العامـة

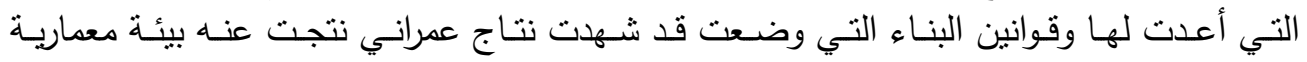
مضطربة سواء في مظهرها العام أو في سلوكيات المستعملين لهاء التهاء

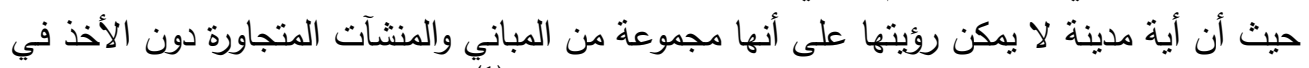

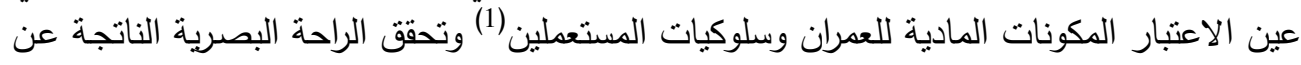

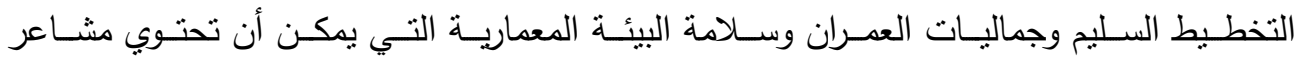

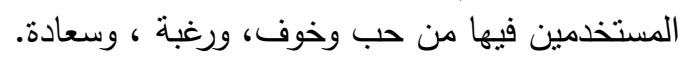

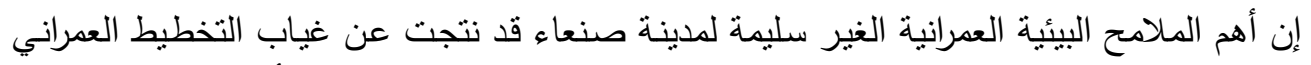

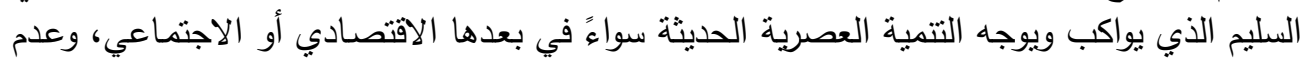

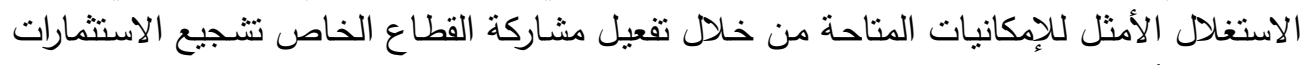
المحلية والأجنبية.

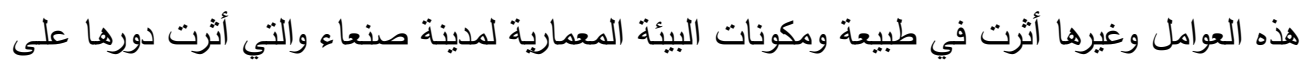
المظهر العام للمدينة وعلى ساكنيها وزوارها.

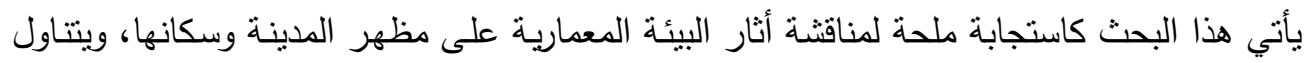

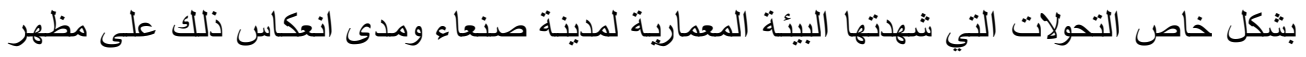

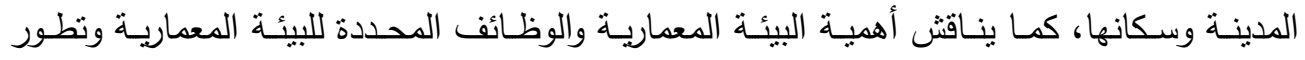

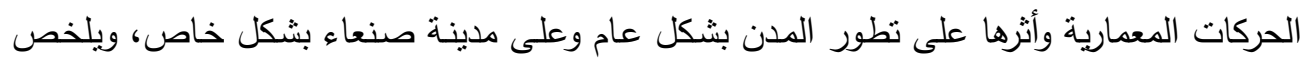
البحث إلى مجموعة من النتائج والتوصيات.

\section{: 1-1}

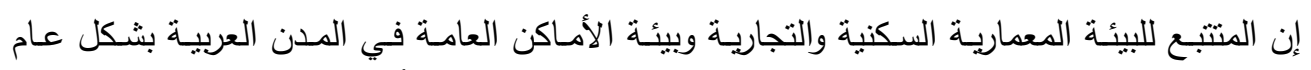

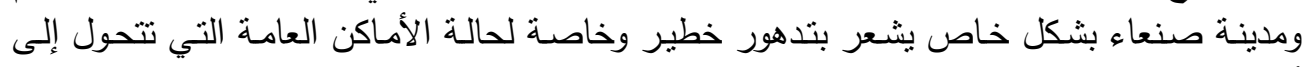

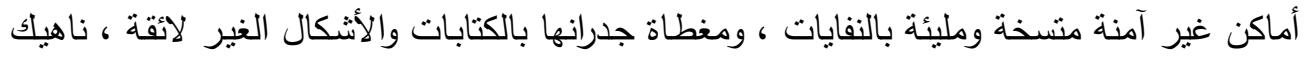

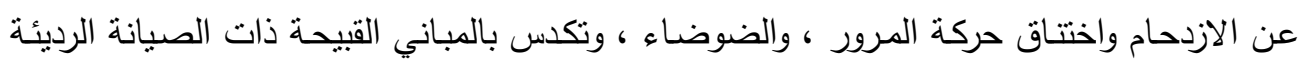

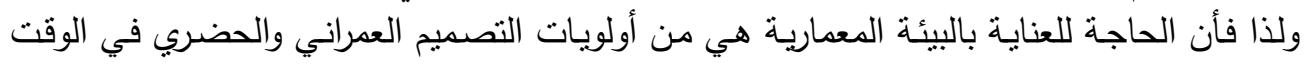

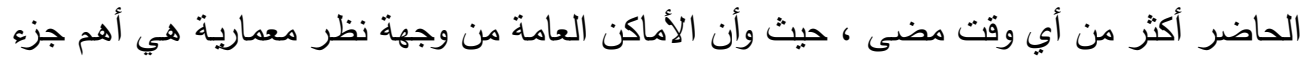

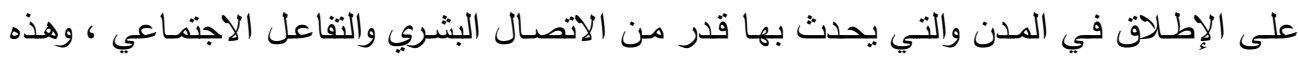

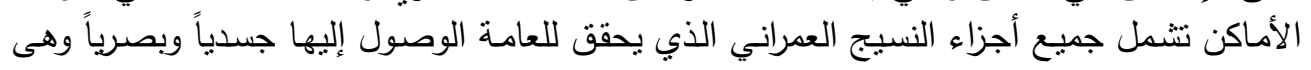

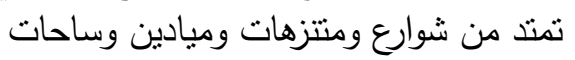

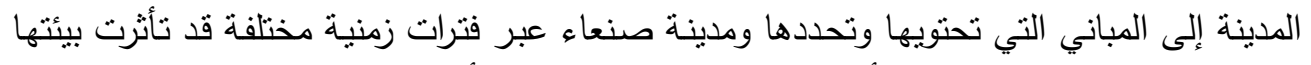

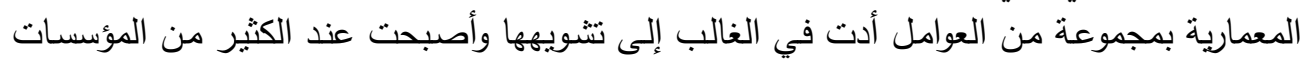

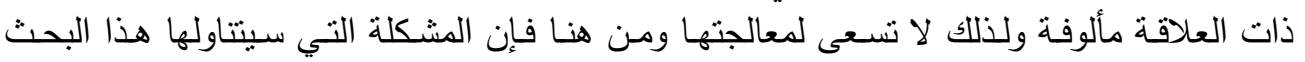

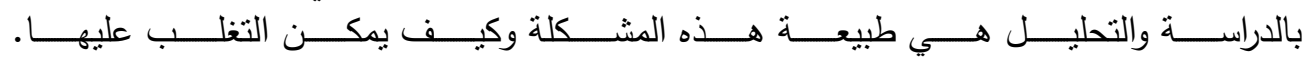




\section{2-1}

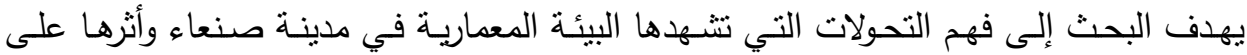

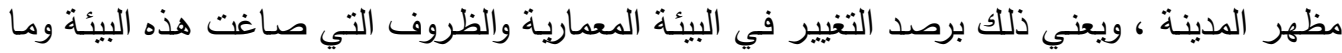

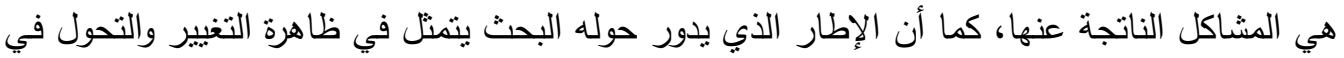

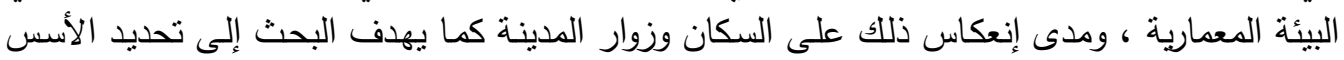

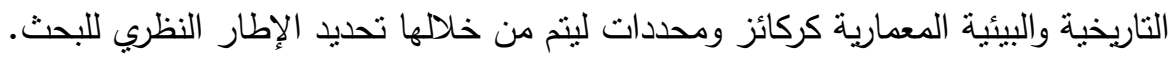

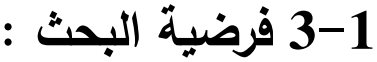

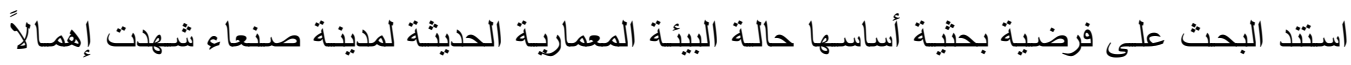
للجوانب الإنسانية في تخطيط الددينة أدى إلى ضعف الروابط الاجتماعية بين سكان المدينة واستشراء

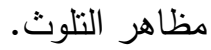

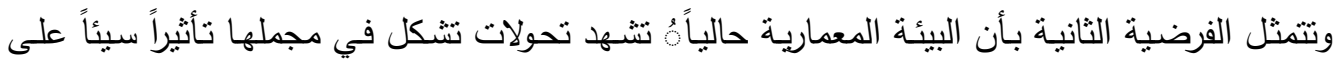

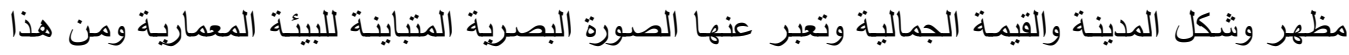

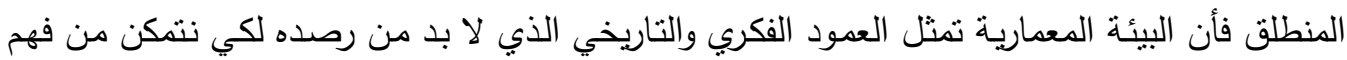

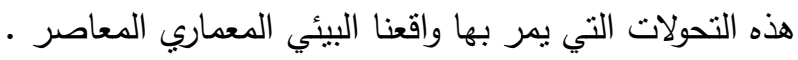

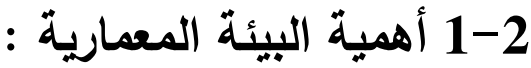

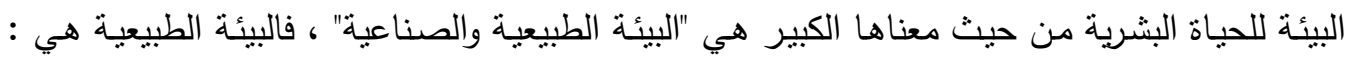

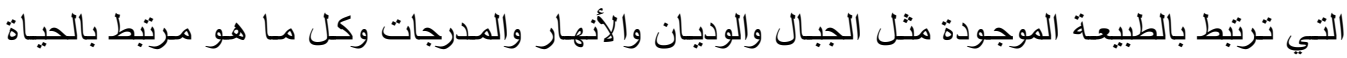

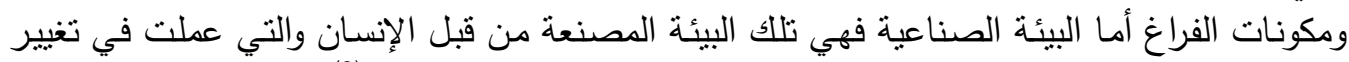

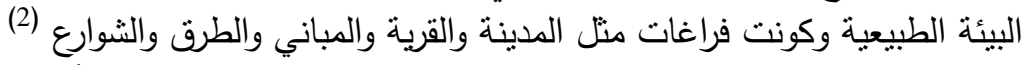

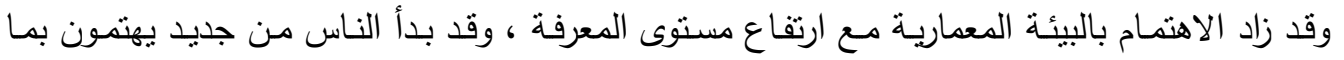

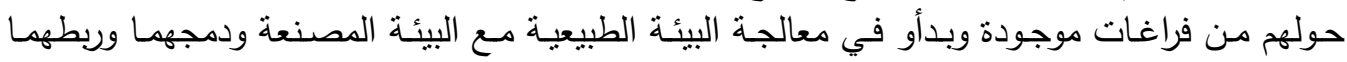
والعمل على انسجامها ، ودراسـة العلاقة فيما بينهما ـ كما حاولوا تعميق الحئة الحفاظة على البيئة الطبيعية

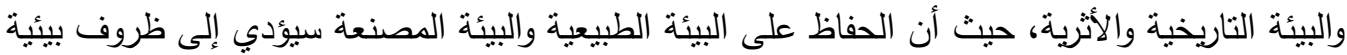

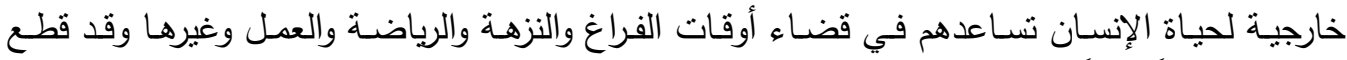

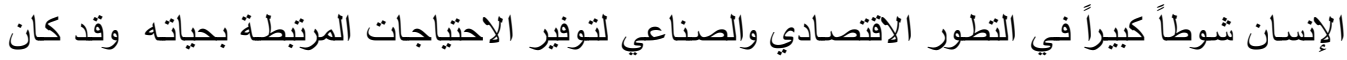

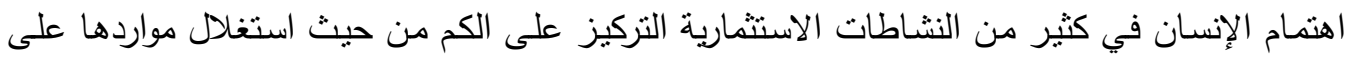

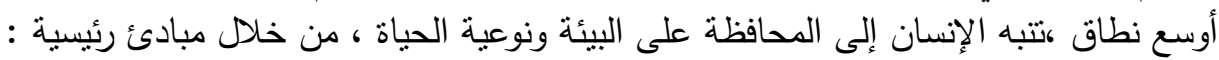

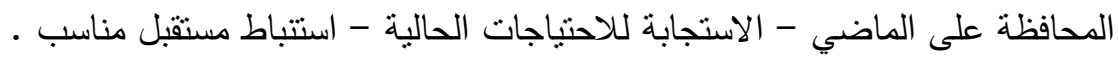

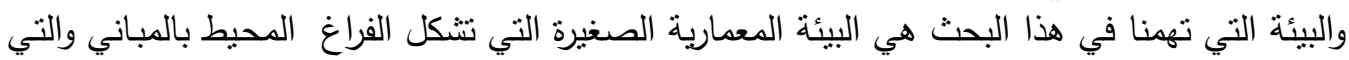

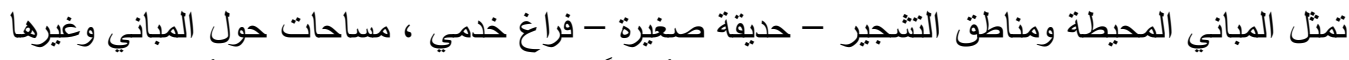

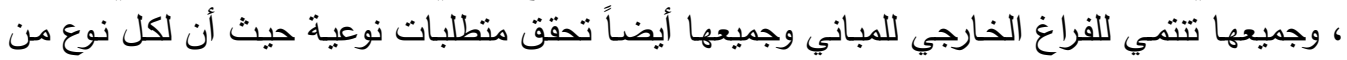

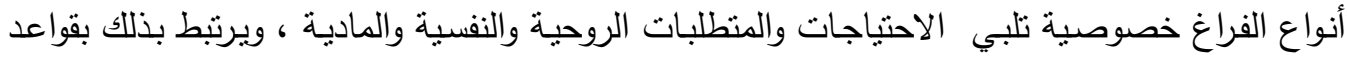

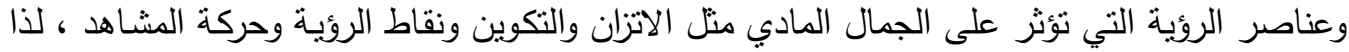

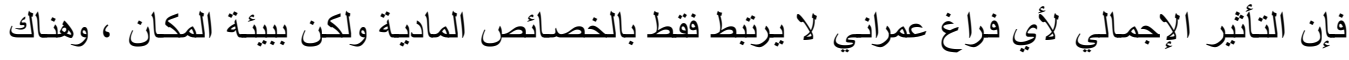

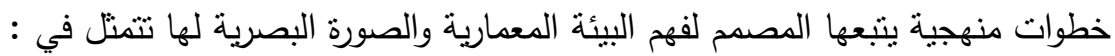




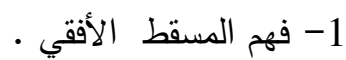

2- ارتفاع المباني المحيطة بالفراغات ونسبها بالأبعاد الأفقية .

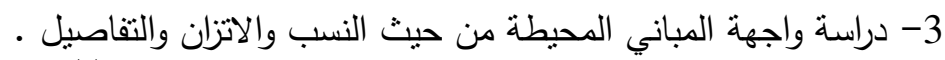

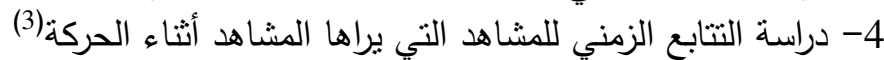

\section{2-2 الوظائف المحددة للبيئة المعمارية المنية}

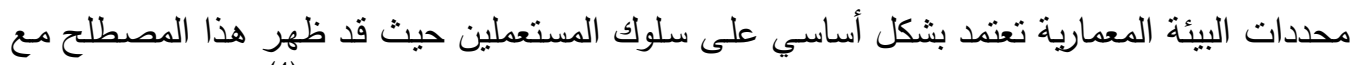

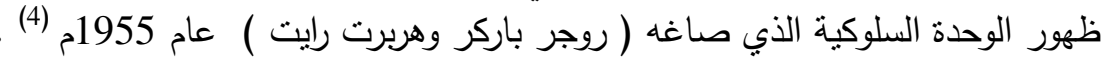

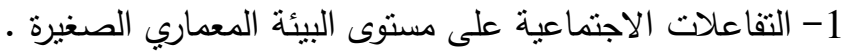

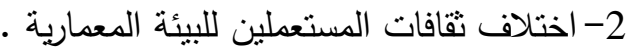

3- البيئة المعمارية هي المكان الذي نعيش فيه. والتتمية هي ما نحاول جميعنا تحقيقها والاثتان الانية مرتبطتان ولا تقبلان التجزئة والاهتمام بالبيئة هدف مشترك من أجل استمرار البقاء فهناك استحالة التحالة أبدية لفصل قضايا التتمية والبيئة المعمارية.

4- التطور المستمر للحياة أظهر مشاكل بيئية زاد من اهنمام الناس تدريجياً بالبيئة وخاصة بيئة النئة

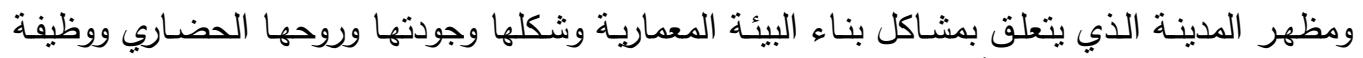

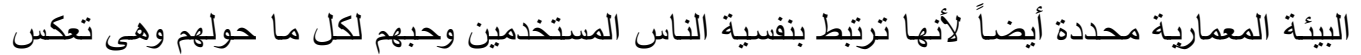

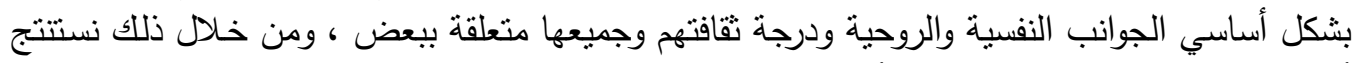

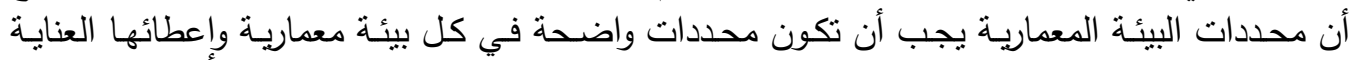
الفائقة للتطوير والتأهيل لتمييز مظهر المية المدينة.

\section{3- تطور الحركات المعمارية والتخطيطية للبيئة المعمارية :}

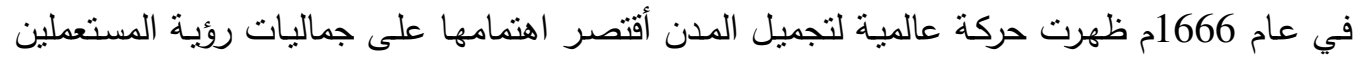

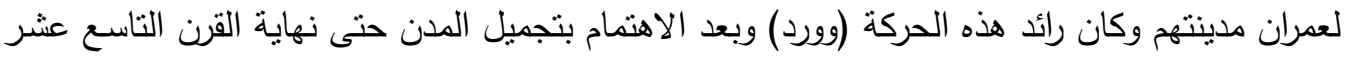

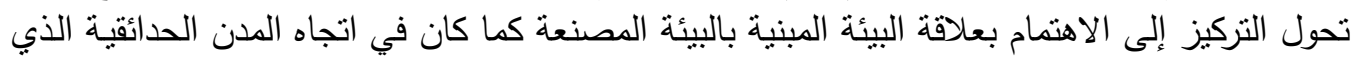

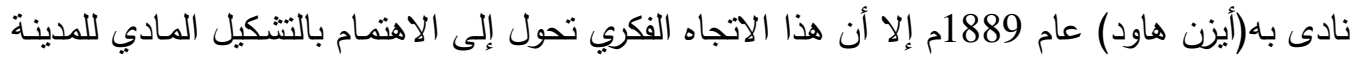

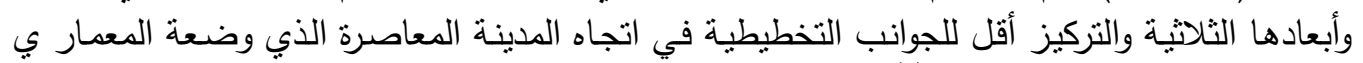

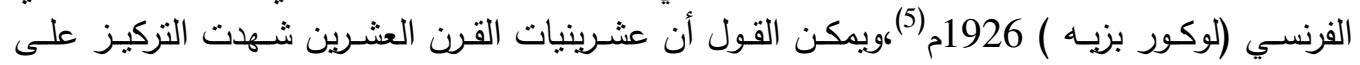

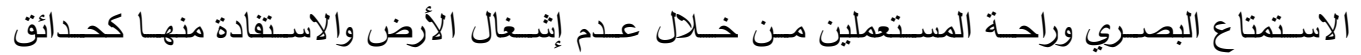

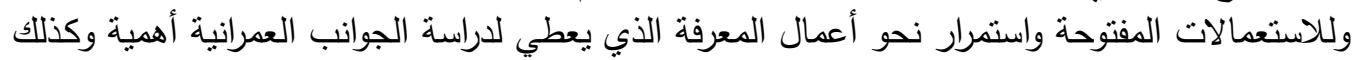

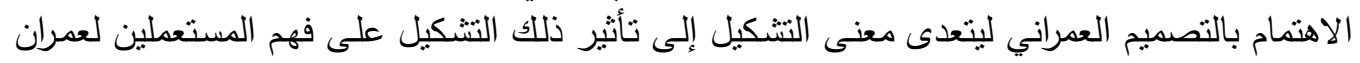

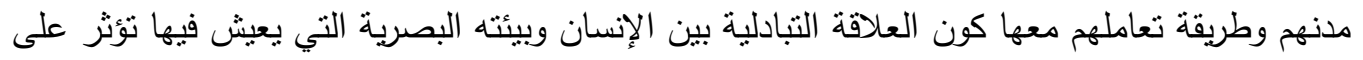

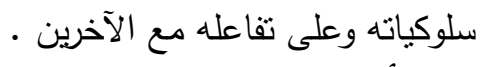

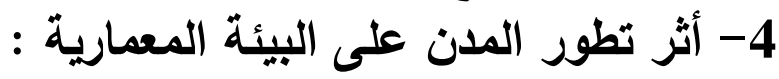

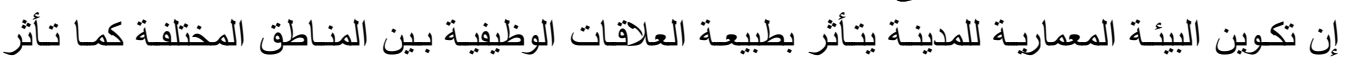

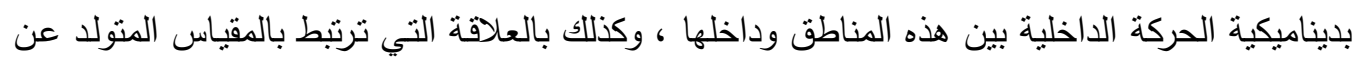

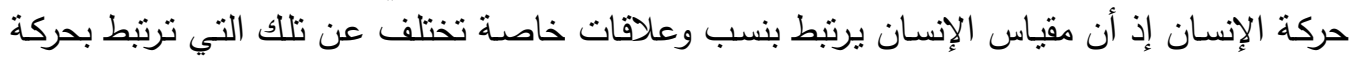


السيارة لذا فإن حجم الفراغات في البيئة المعمارية تزداد بالتدريج بزيادة سرعة السيارة التي يستقلها داخل

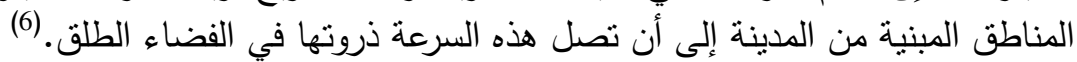

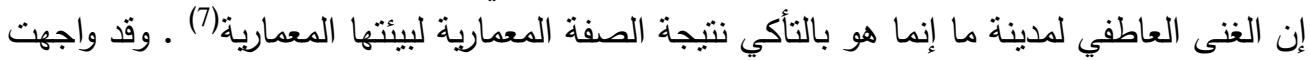

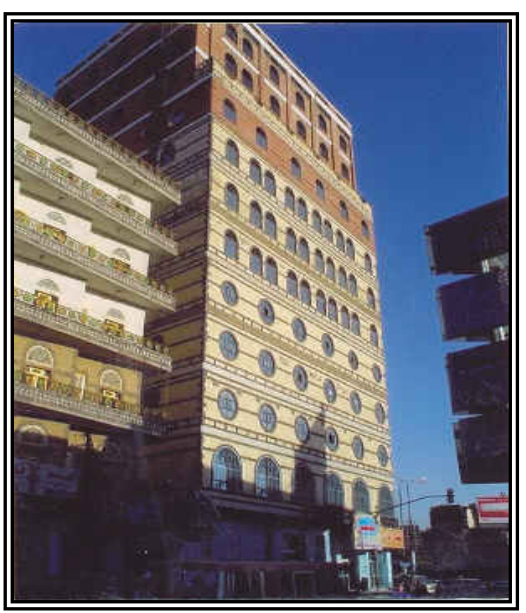

شكل رقم (1) حركة المرور وأثرها على الثشارع

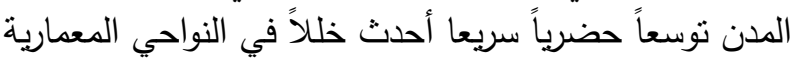

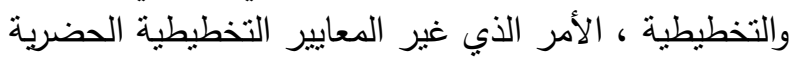

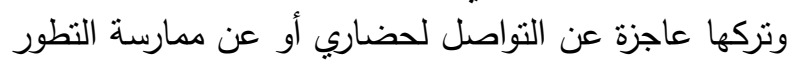

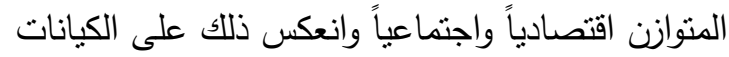

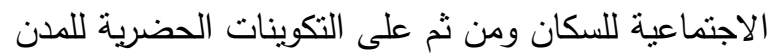

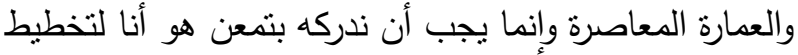

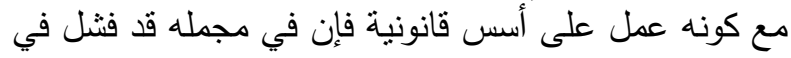

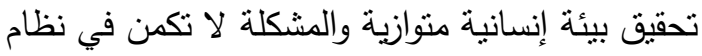

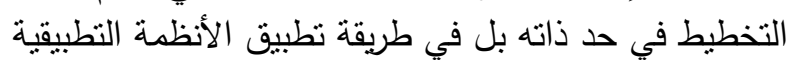

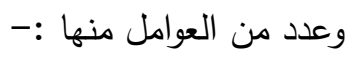
عدم تفهم أفضل للنمو الطبيعي للمدينة حيث يستغرب الإنسان

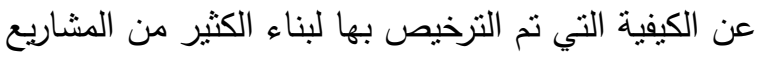

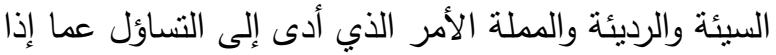

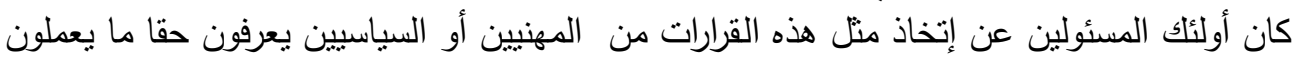

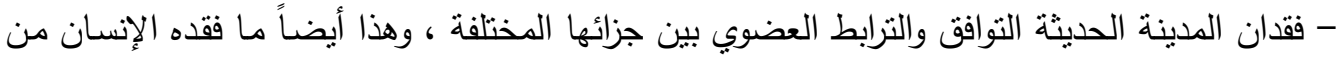

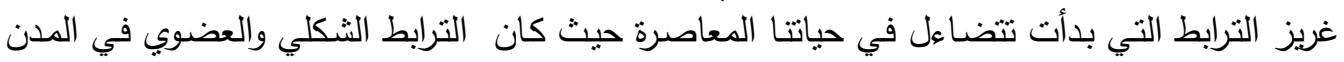

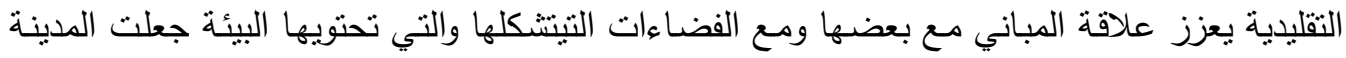

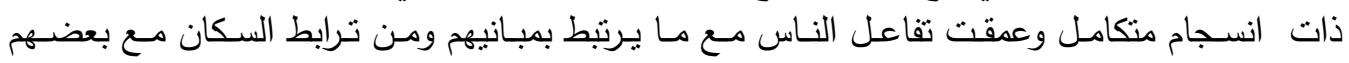

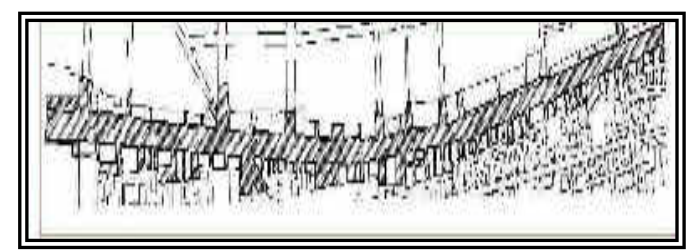

شكل رقم (2) كثرة التقاطعات وأثرها على حركة 


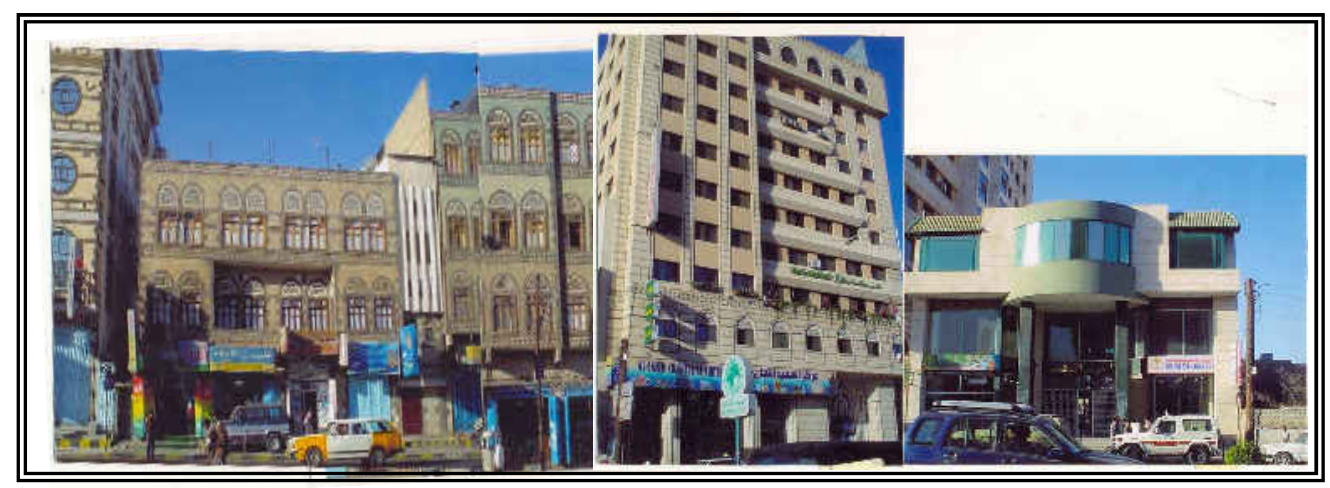

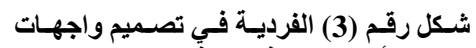
المباني أدت إلى هذا التنافر المصدر الباحث

وهذا يختلف كلياً مع ما جاءت به الددينة الحديثة ، حيث أصبحت البيئة المعمارية تحتوي على مباني منفردة غاب عنها الانسجام والتكامل.

تأكيد الذاتية والفردية للمبنى الواحد والتتكيل العمراني الغير متجانس للمدينة ككل فاختل التوازن ،

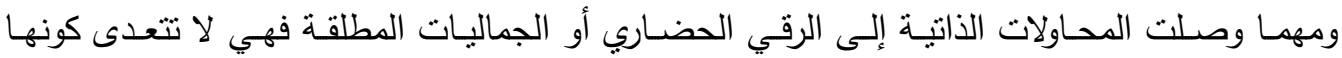
محاولات فردية لا تعبر عن كيان المجتمع أو تشكل المدئ المدينة.

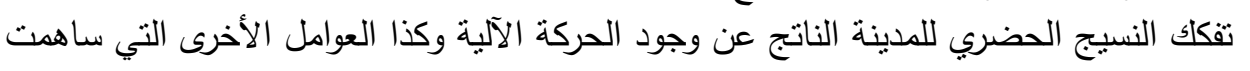

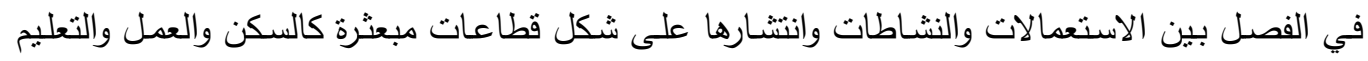

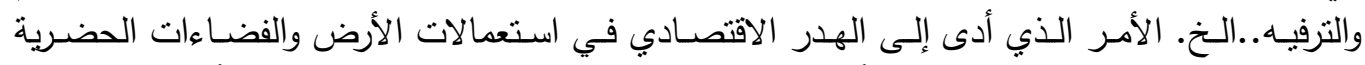

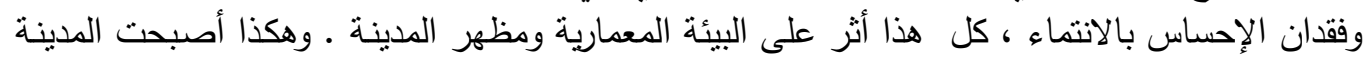

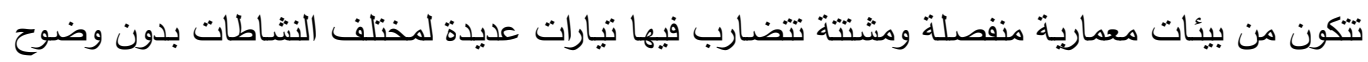

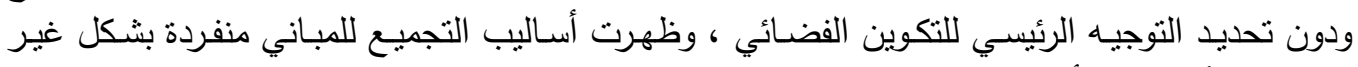

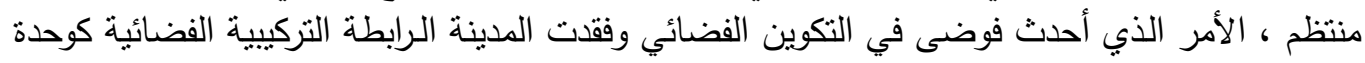

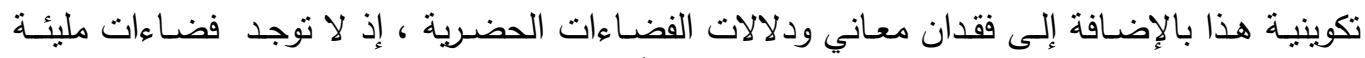

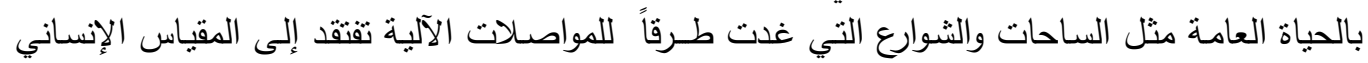

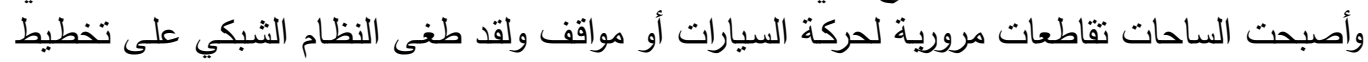

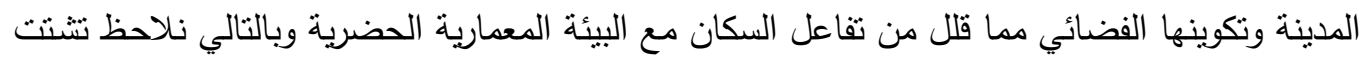

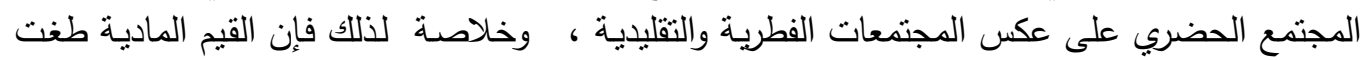

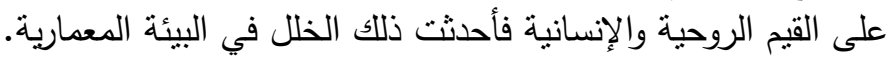

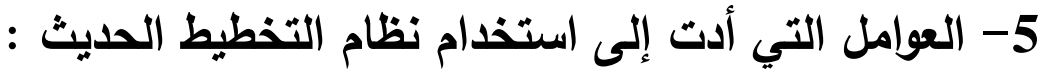

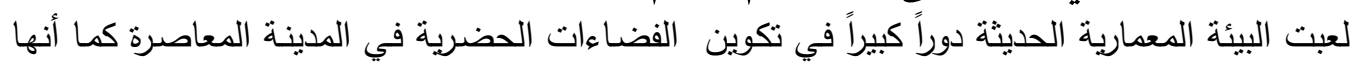

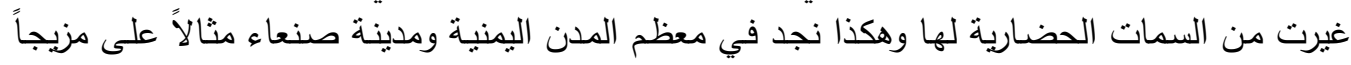

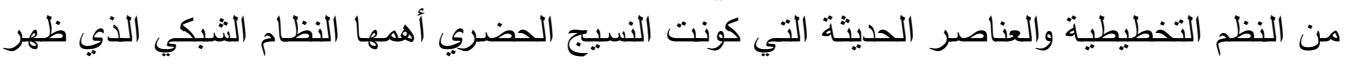

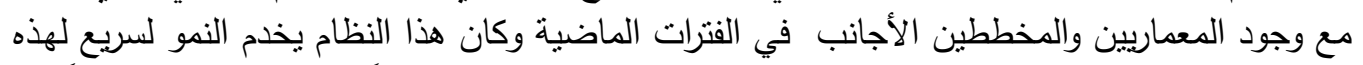

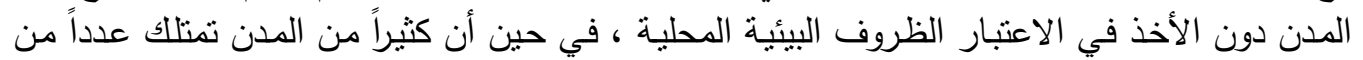


الخصائص البارزة التي هي جزء من خصائص وتخطيط المدينة المتجانس حيث تجمع في خصائصها

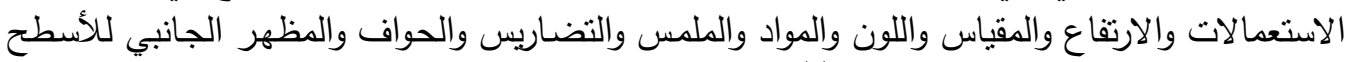

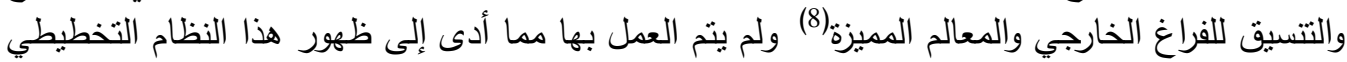

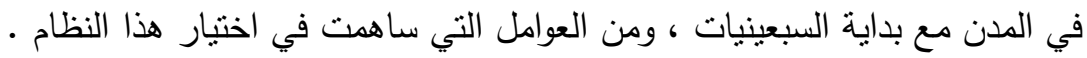

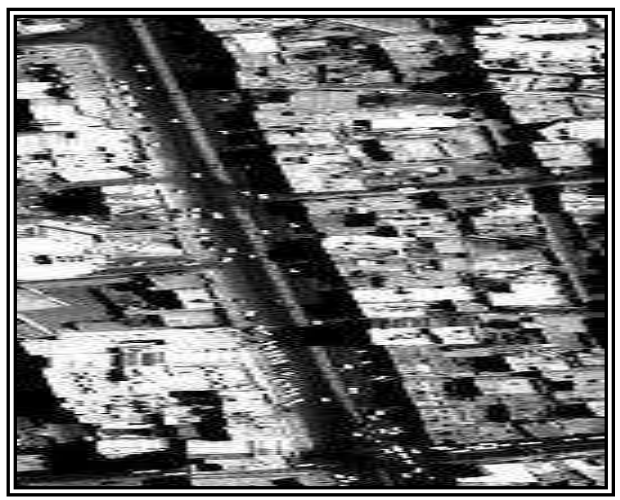

الثكل رقم (6) التخطيط الثبكي وأثرة على البيئة المعمارية المصدر صورة جويةً مصلحة المساحة الثنة

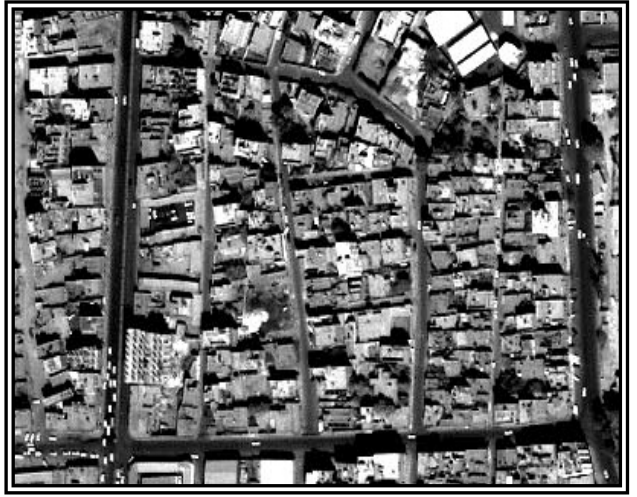

الثكل رقم (5) الفردية في التجميع المصدر مصلحة الساحة

1- زيادة الهجرة من الريف إلى المدينة ، كانت وما زالت أحد أهم العوامل التي تؤثر على البيئة

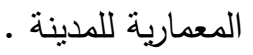

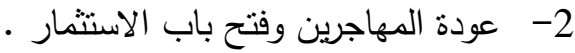

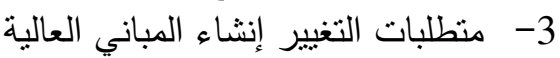

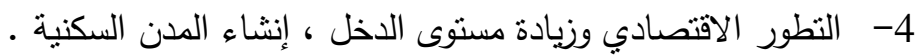

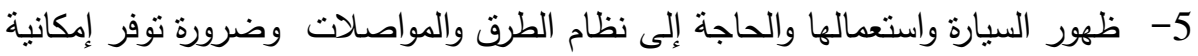


مشاكل مرورية.

6- زيادة عدد السكان في الددن ومـا تطلبه من توسع في البنية التحتيه والحاجة إلى نظام تخطيط

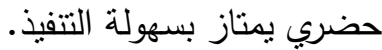

7- اختلاف وتغير الهيكل الاقتصادي للمجتمع والعلاقات الاجتماعية ومستويات المعيشة.

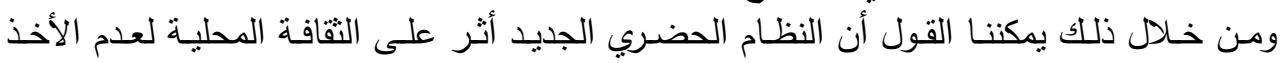

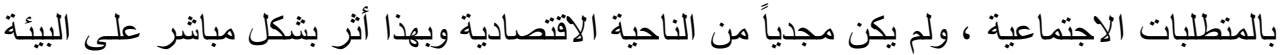

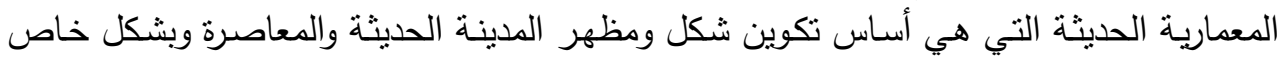
مدينة صنعاء والتي بسعى الجميع سواء المختصين والمسئولين إلى تحسينها .

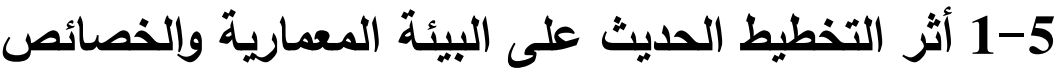
التخطيطية والمعمارية :

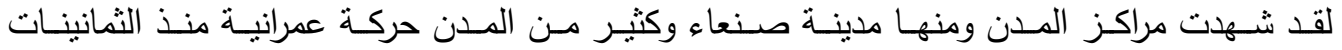
والتسعينات من القرن الماضي تغييرات لم يسبق لها مثنيل في 


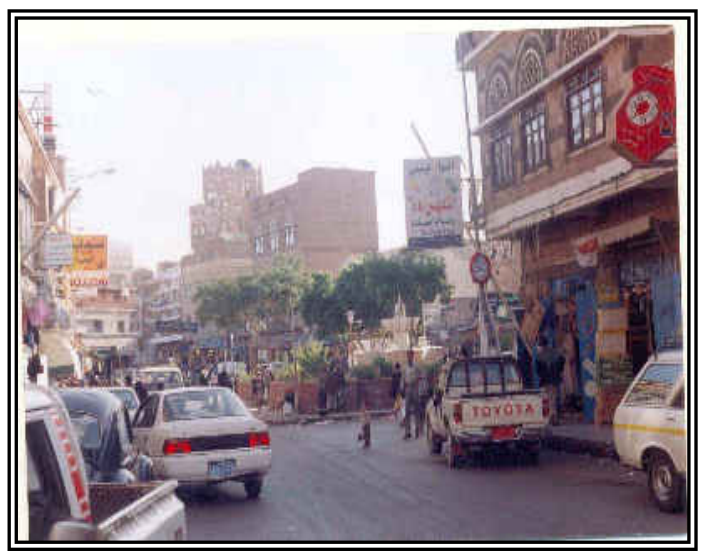

الثكل (8) الحركة المستمرة و أثرها على بيئة الساحة المصدر الباحث

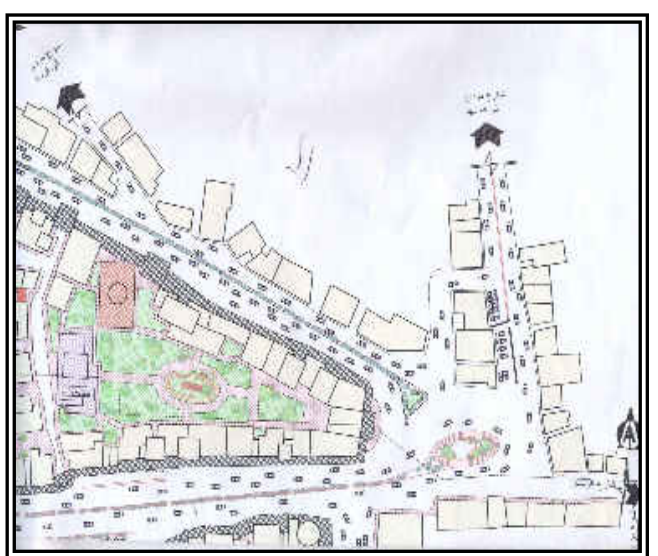

الثكل رقم (7) ضيق المكان وكثرة إتجاه الحركة

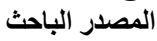

الحجم بما يتعلق من تطوير المباني الحديثة وإنشاء الطرق ونتج عن هذه العمليات التطويرية قدراً كبيراً

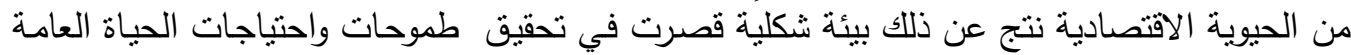

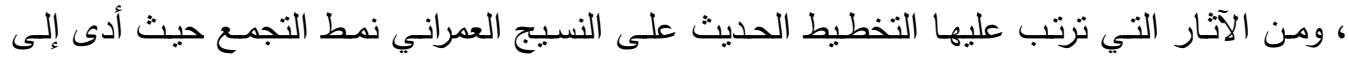

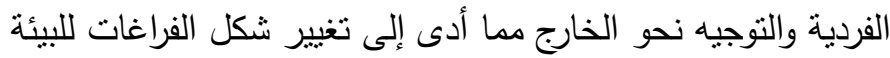

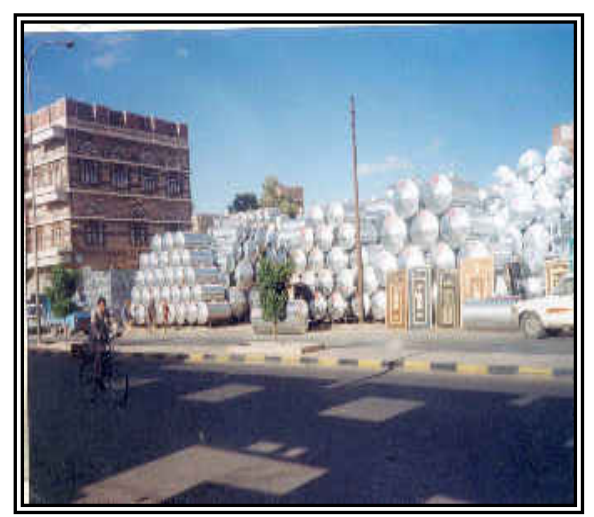

شكل رقم (9) أثر الصناعة الخفيفة على بيئة الثارع

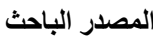

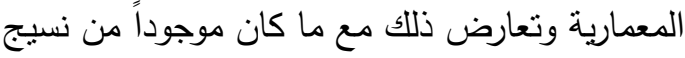

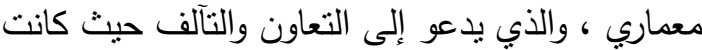

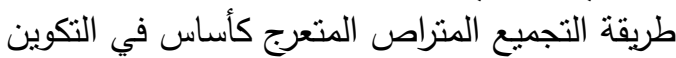
وكان لها أثز على نفسية ومشاعر الإنسان أما التخطيط الترانين

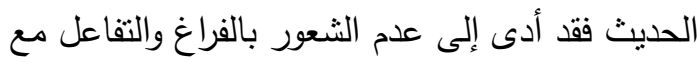

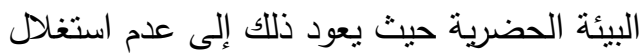
التواتر بين الأجزاء الحديثة والقديمة بشكل إيجابي الئي

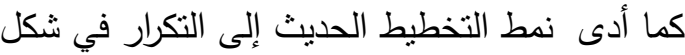

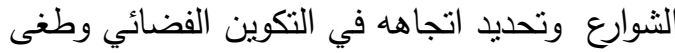

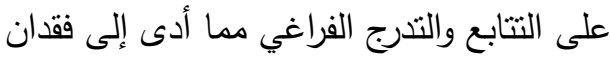

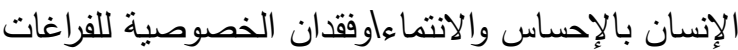

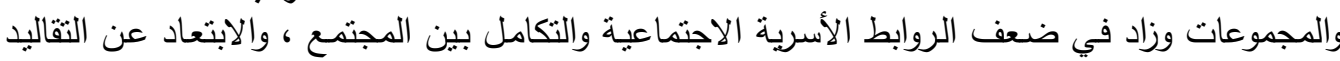

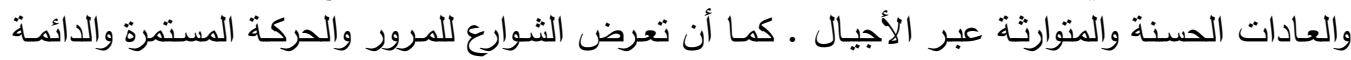

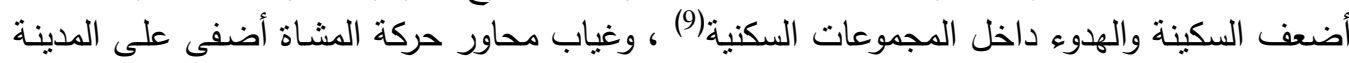

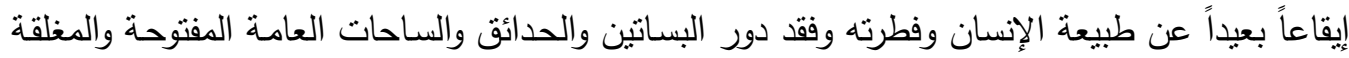

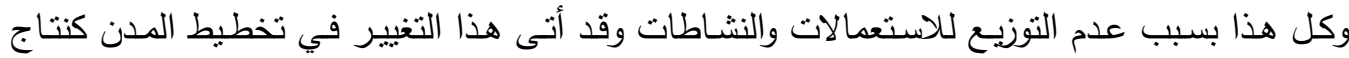

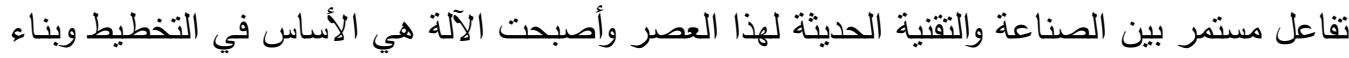

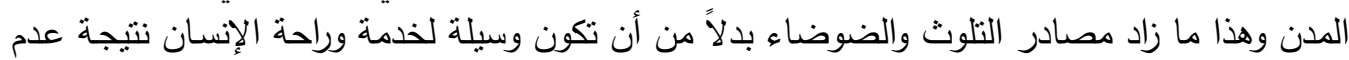
الالتزام بقوانين التخطيط وقد شمل هذا التغير الكثير وخصوصاً عندما حدث هذا التغيير بحت بحم كبير

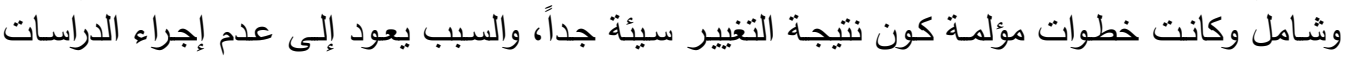




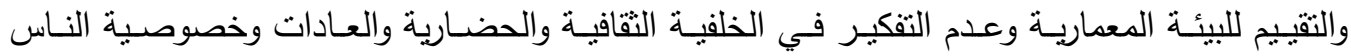
واستعمالاتهم واحتياجاتهم وجعل البيئة المعمارية تعبر وتعكس الخصوصية النقافية وتعكس صورة مدينة صنعاء.

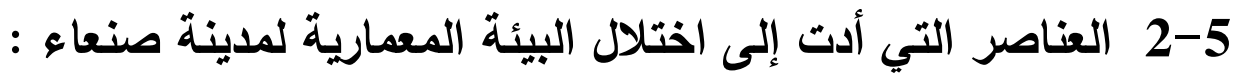

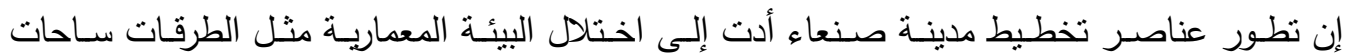

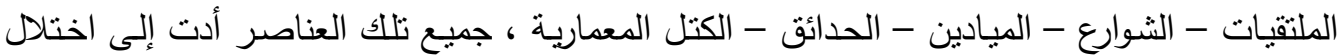

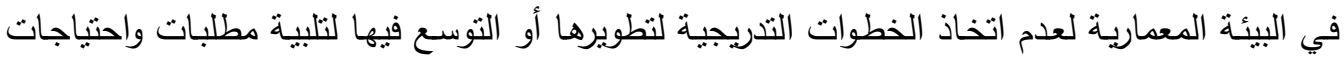
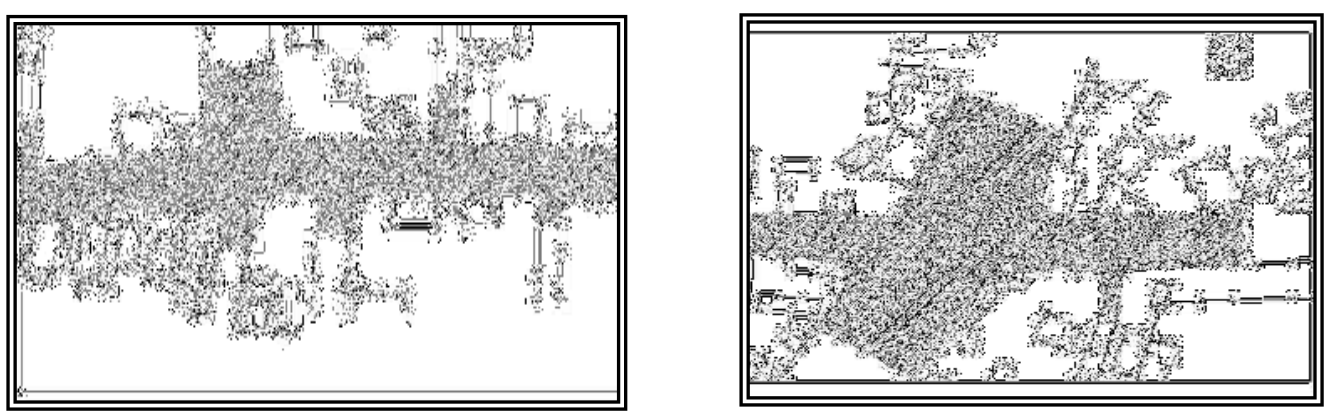

شكل (9) التقاطعات وتدرج الثوارع المصدر الباحث

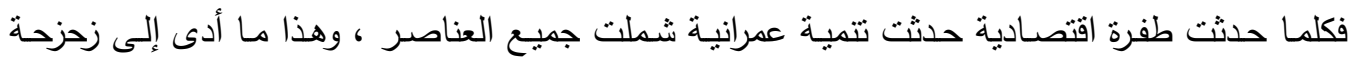

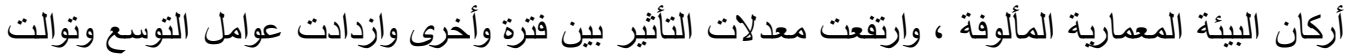

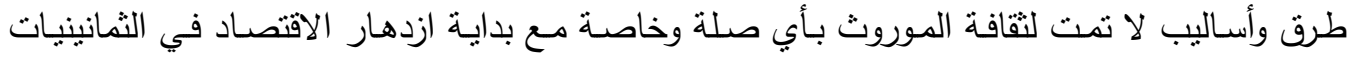

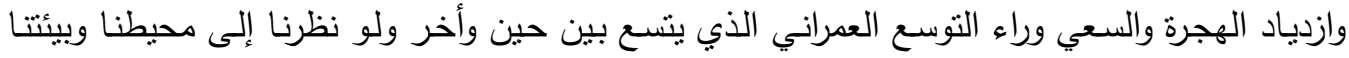

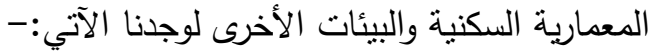

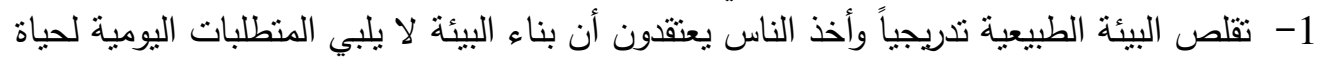

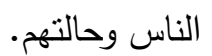

2- انخفاض مستوى تصميم المدينة والذي ينبع بشكل كبير من طبيعة وخصائص الفراغات المفتوحة

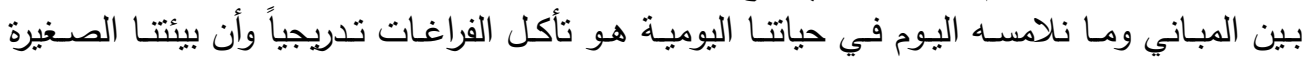

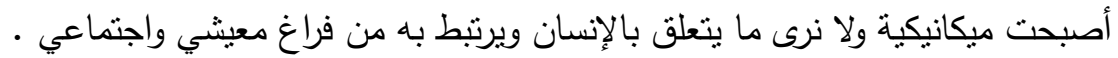

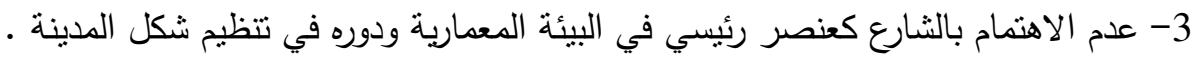

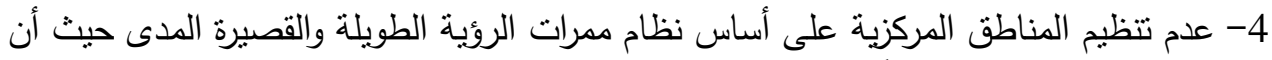

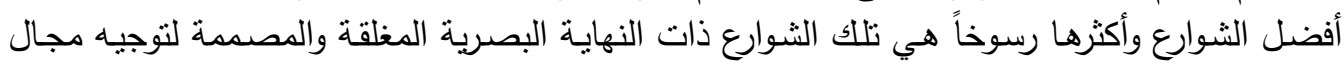

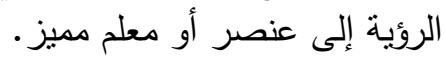
5- القصور في عملية التصميم المتكامل لشوارع المنشاءات التجارية وظهورها في شكل غير 
موحد ، ويمكننا مشاهدة ذللك من خلال المظهر العام للشارع حيث يلاحظ أن لكل متجر شكل ونوع

من أنواع الديكور (10).

6- شوارع مخصصة للششاة في المناطق التجارية لتلبية احتياجاتهم اليومية وعدم الاهتمام بجودة المستوى البيئي للشوارع الخاصة بالششاة بشكل واضح.

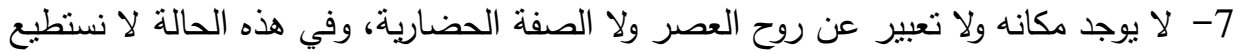

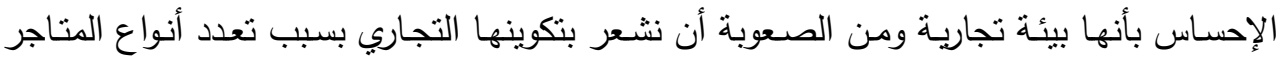

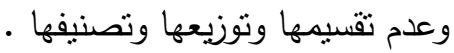

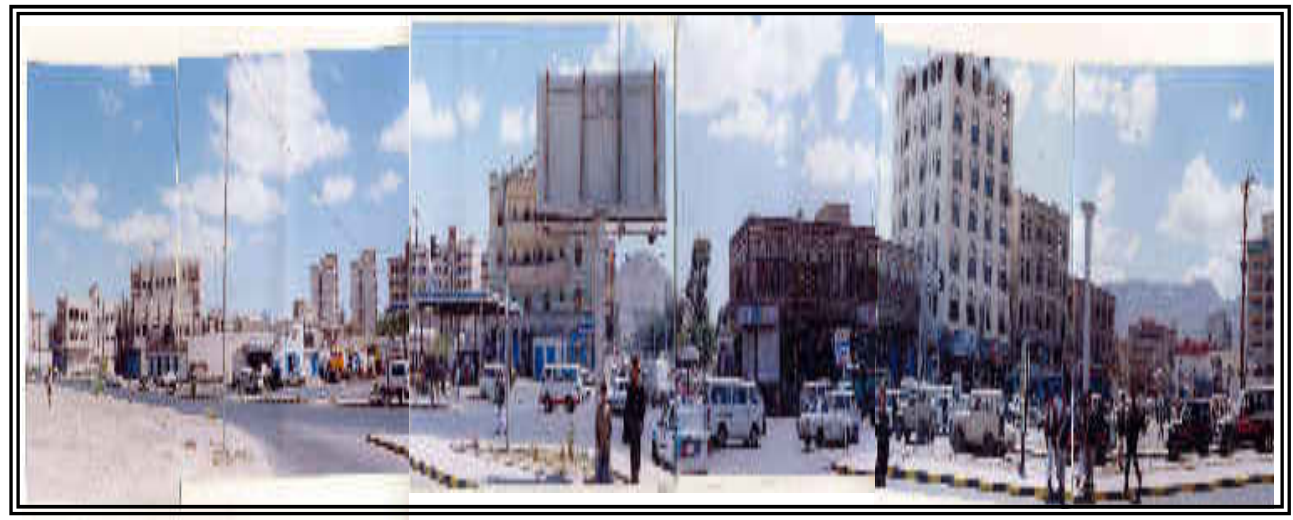

$$
\text { شكل رقم (10) بيئة البساحات والملتقيات }
$$

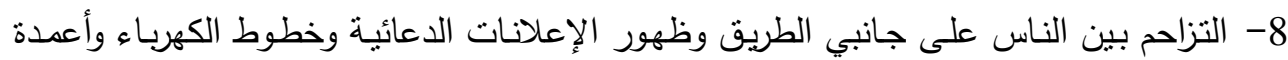

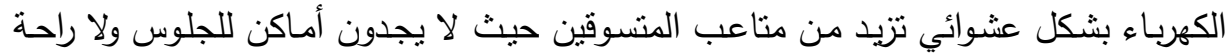

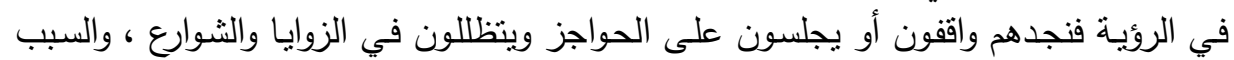

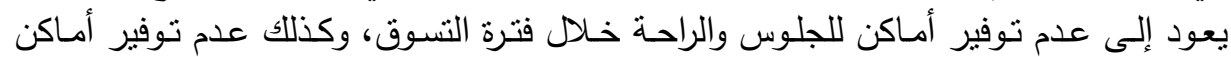

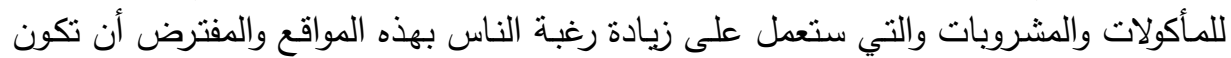
ذات جودة عالية في التصميم. 9- عدم الاهنمام بالطابع المعماري العام للبيئة المعمارية الذي هو أساس مظهر المدينة، وكذلك

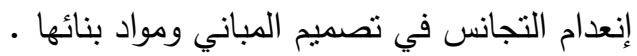

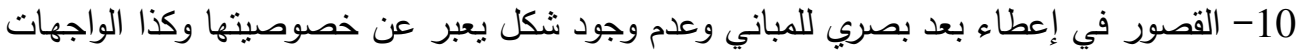

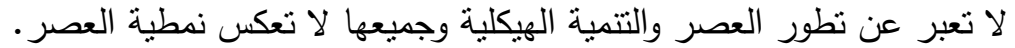

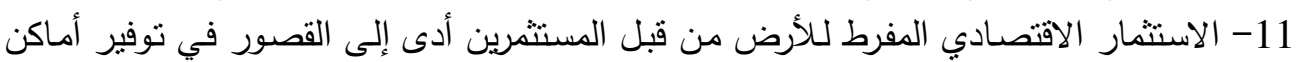

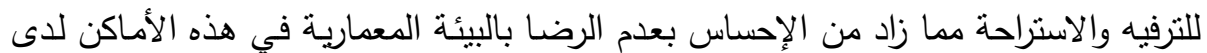
الناس المترددين عليها. 12- القصور في التشجير وعدم وضعها في الحسبان بحيث تقوم بعملية تزيين الثوارع 
التجاريـة وعمل مسطحات خضراء وعمل الجزر الوسطية للمزاهر ، والمجسمات الجماليـة ،

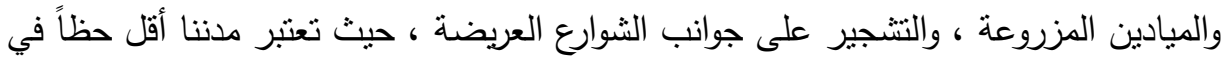

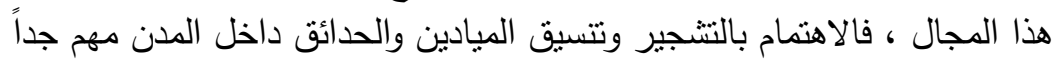

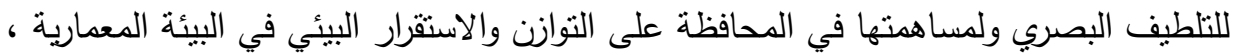

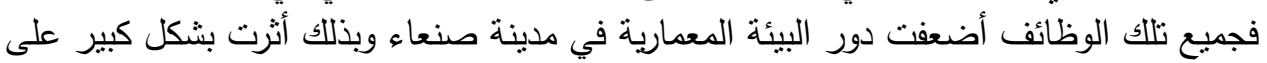

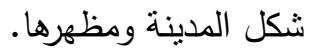

\section{5-5 البيئة المعمارية للمدن اليمنية القديمة :}

لقد كانت البيئة المعمارية في المدن اليمنية بيئة ترتبط بحياة الإنسان وأنشطته المختلفة وكان لها لهان المعاني

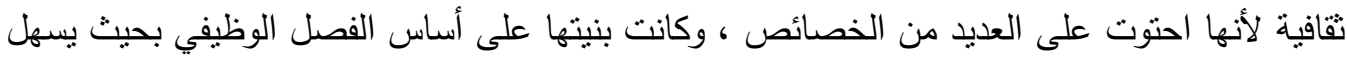

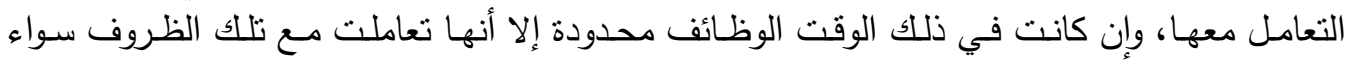

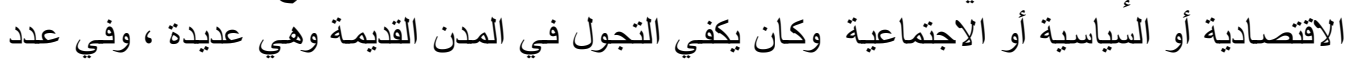

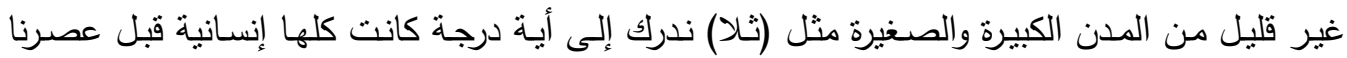

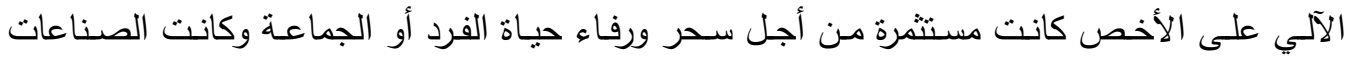

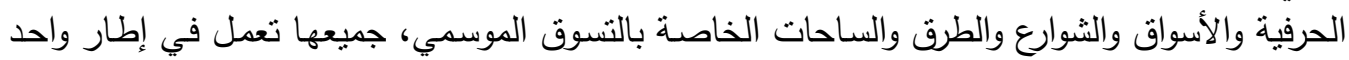

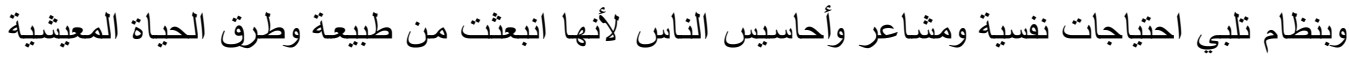

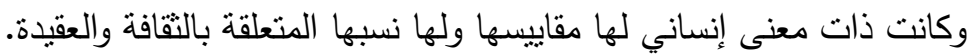

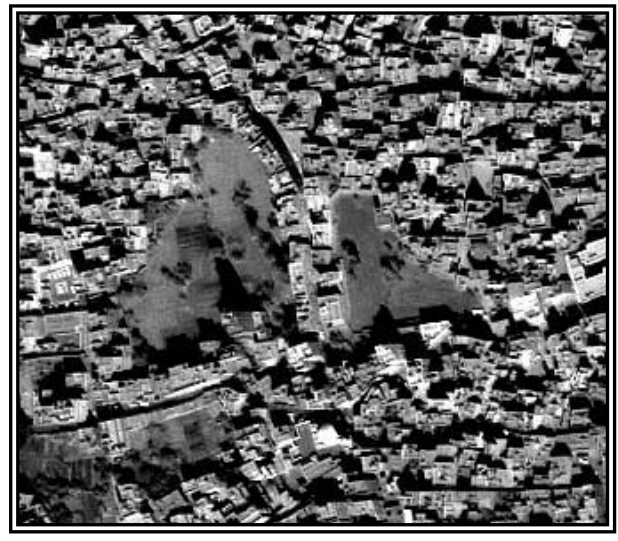

شكل رقم (11) البيئة المعمارية السكنية لصنعاء القديمة المصدر صورة جوية مصلحة المساحة لصنة الصنية

5-4 مشاكل البيئة المعمارية المعاصرة

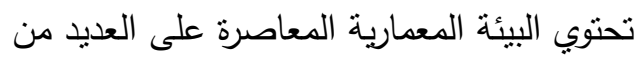

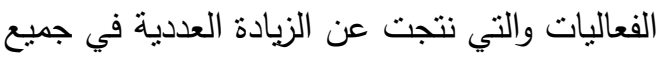
العناصر التي تكونت منها البيئة المعمارية - منها:

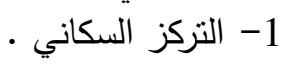

2- - زيادة مساحة الطرق والتكدس في الثوارع.

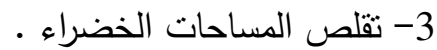

4- التعدي على المناطق الزراعية .

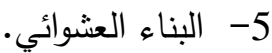

تداخل الصناعات بين الأحباء السكنية كل تلك الكئن

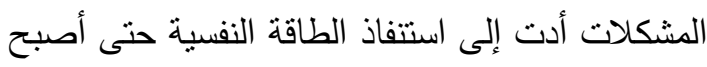

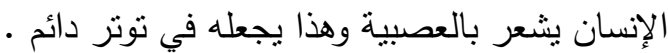

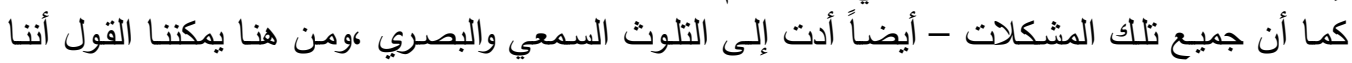

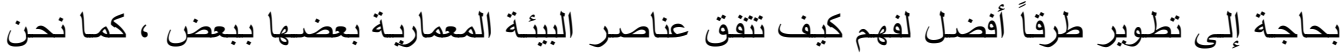

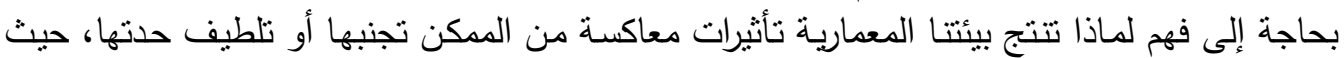

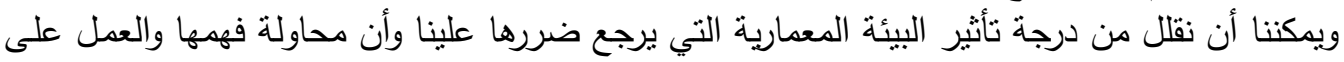
تحسينها سوف تكون تجربة مجزية. 


\section{5- 5 آثار البيئة المعمارية الحديثة على الإنسان :}

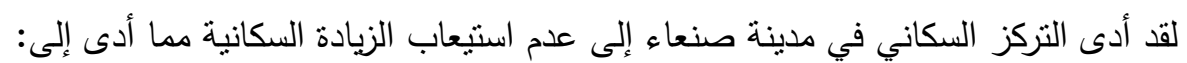

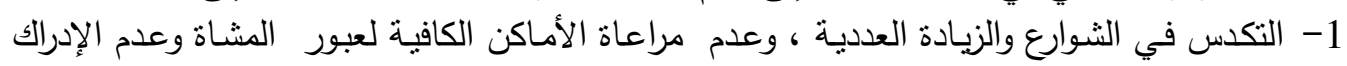

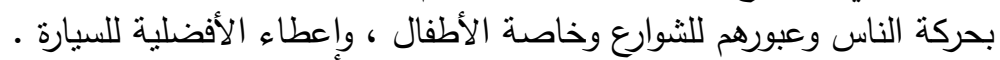

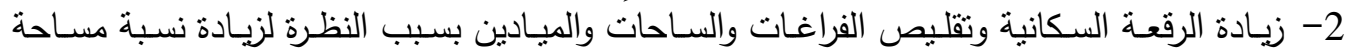

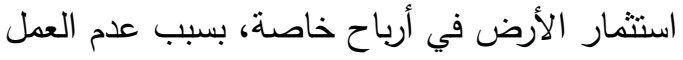

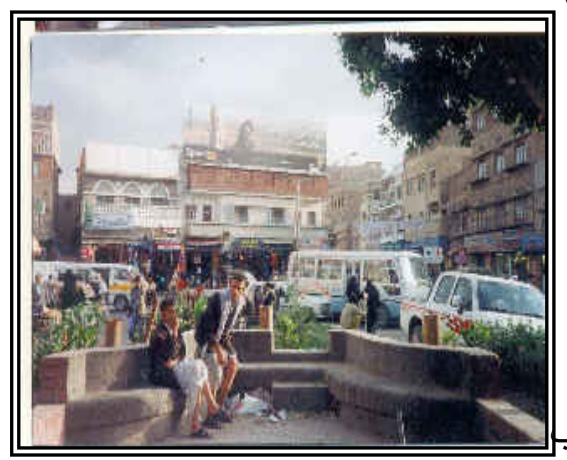

بالمعايير التخطيطية للبيئة المعمارية.

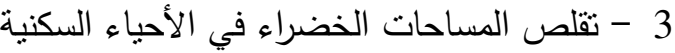
والتوسع في الطرق وانعدام الأماكن الترفيهية الأبية

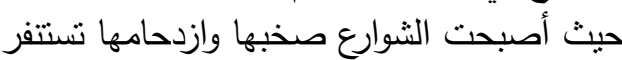

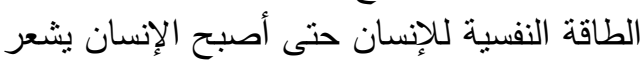
بالعصبية والتوتر الدائم والثعور بالخوف الطان الإنسان

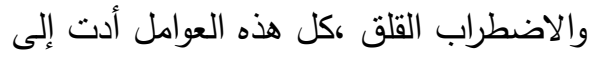
أيضاً جعلت الناس يشعرون بالهموم وعدم لشعورشكل رقم (12) تقلص مساحات الفراغات وأثرها على الصورة البصرية البرات البرات المصدر الباحث

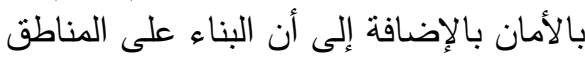

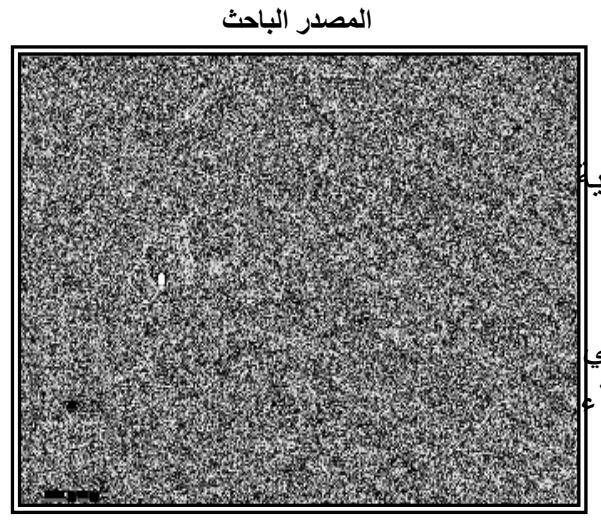

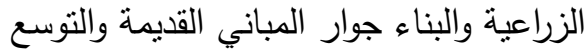
في البناء العشوائي • وتحول القرية الريفية إلى الى العية

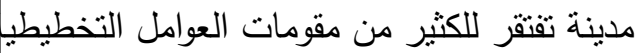

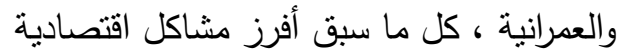

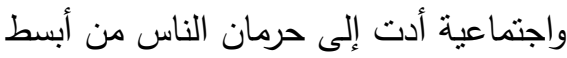

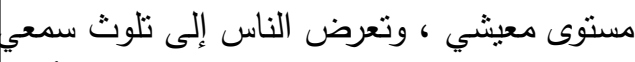

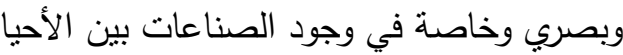

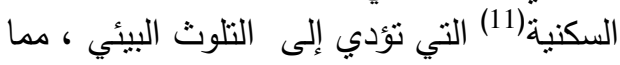

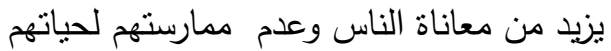

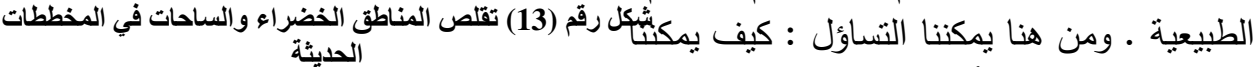



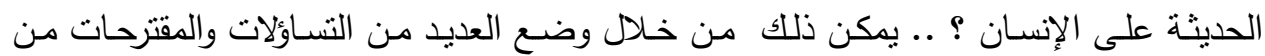

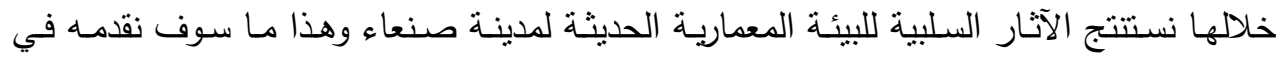

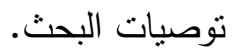




\section{6-5 آثار العناصر التخطيطية على البيئة المعمارية ومظهر المدينة}

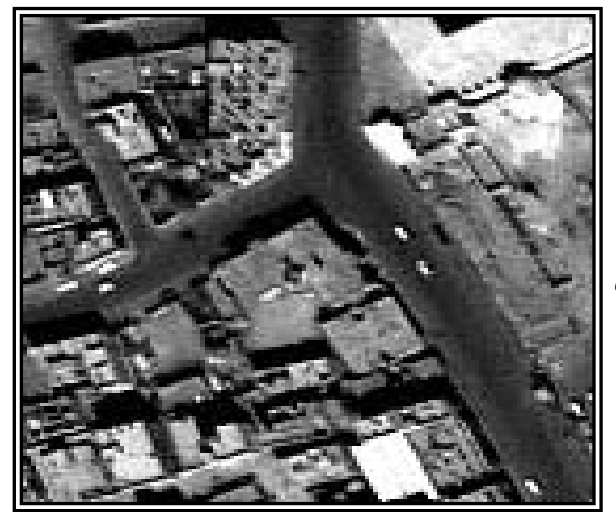

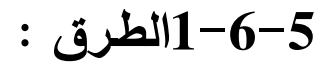

كان لتوسيع الاتصال دور أساسي في عملية توسيع الشوارع والطرق، دور أساسي في توسيع مخطط لأني

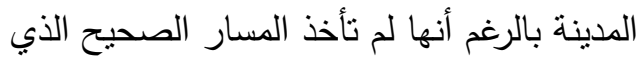

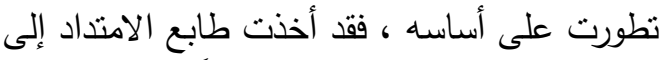

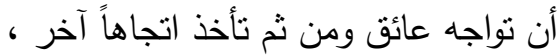

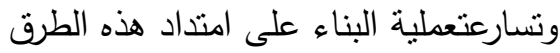

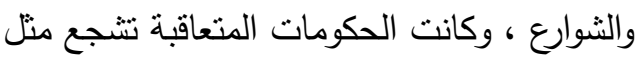

هذه التطورات لكي تبرهن أن هناك تطوراً دون إدراك أن هذا قد يكون هو السبب الرئيسي في

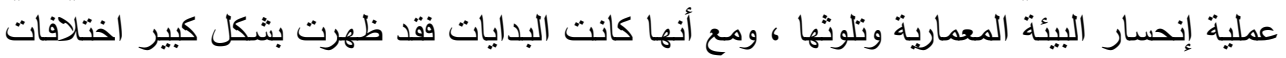

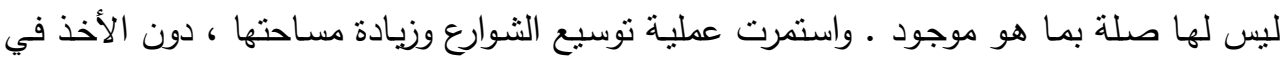

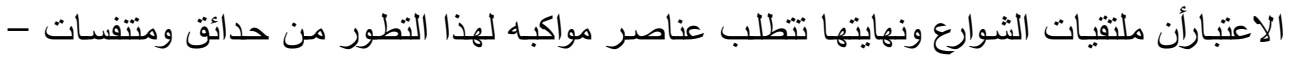
ساحات - ومعالم حتى تعطي انطباع بأن التغير جاء في سبيل نطوير ما هو موجود ، وانطلاقاً

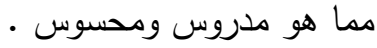
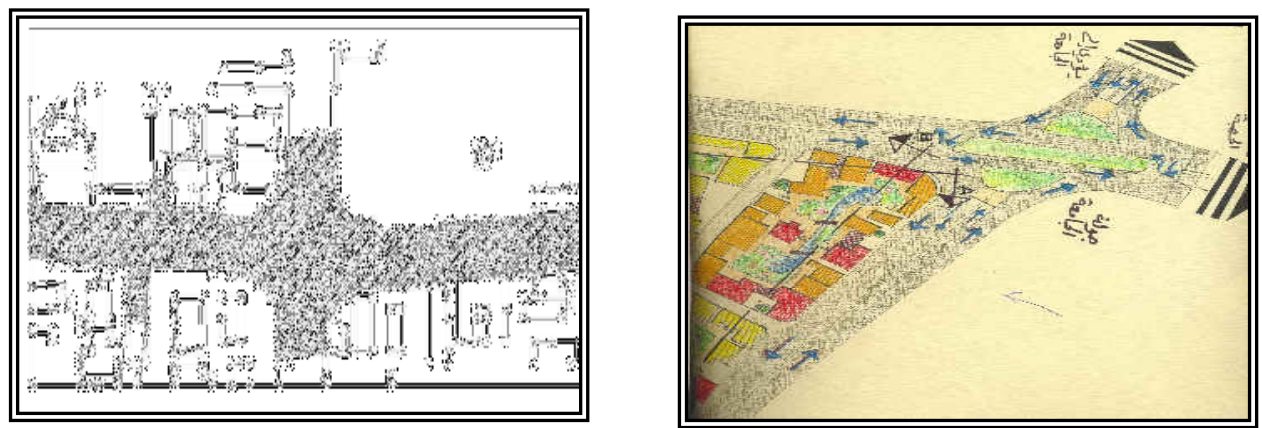

شكل رقم (14) التقاطعات و الملتقيات و الساحات

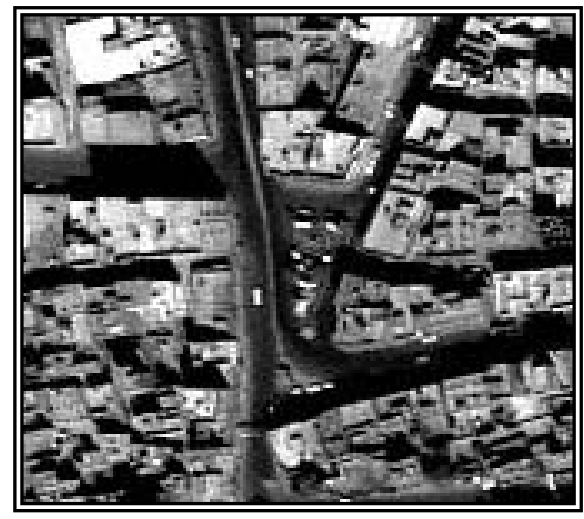

2-6-5 2-6 الساحـات:

الوضع الطبيعي هو إن الساحات لها وظيفة خاصة تتعلق بأنشطة المدينة وفي حالة أن تكون المدينة سياسية فهي تعبر عن الطبيعة والمذاق للنشاط السياسي ، وإن كانت دينية فهي ترنبط بالعقيدة والنواحي الاجتماعية والسياحية وهذا ما تميزت به ساحات المدن القديمة وظهرت في أشكال

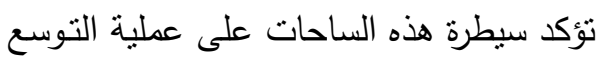

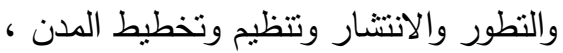
وكانت الساحات تظهر بشكل أساسي في التجمعات 
السكنية وتعمل على استيعاب الأنثطة المختلفة للسكان ، ومع تطور مدينة صنعاء يمكن القول

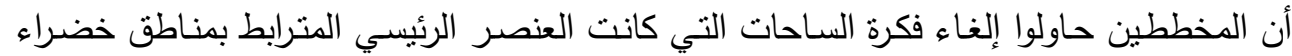

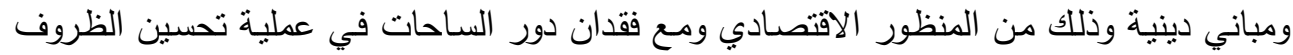

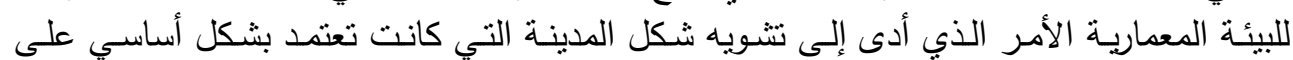
الساحات والبساتين والمعالم الدينية .

\section{3-6-5 الساحات الخضراء ، البساتين والحدائق :}

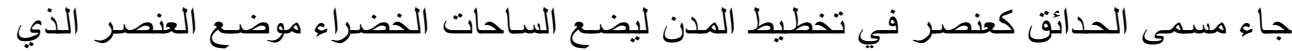

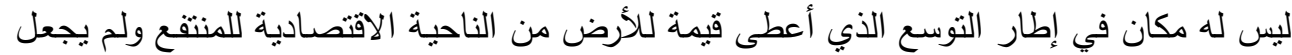

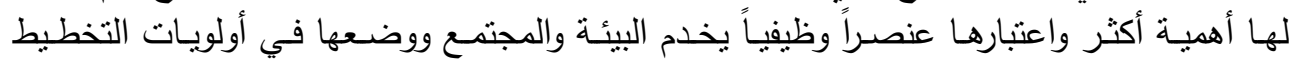

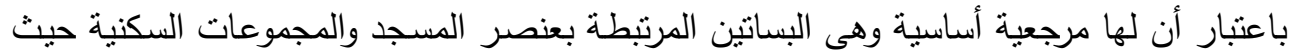

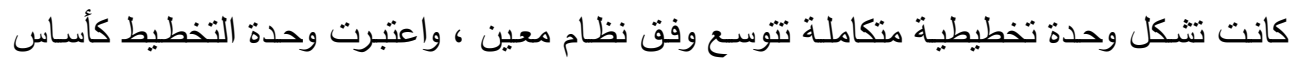

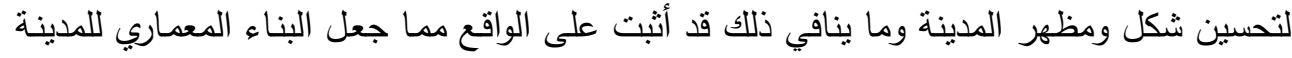
في وضع غير مقبول ومؤثر بشكل أساسي على المين المستقفيدين .

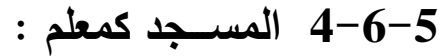

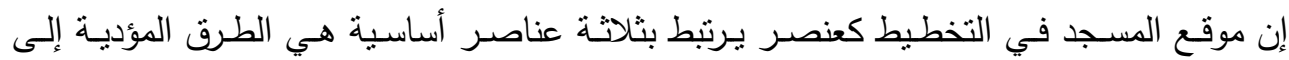

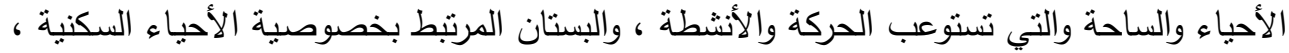

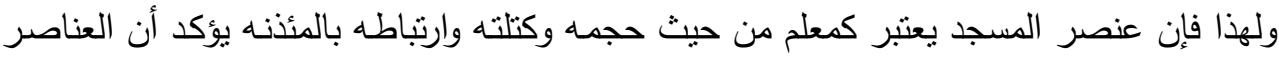

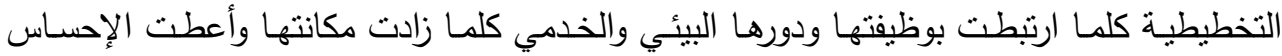

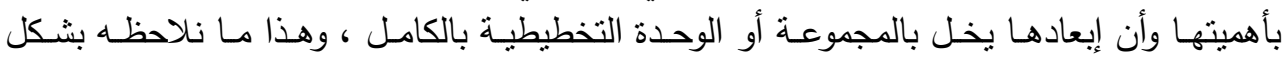

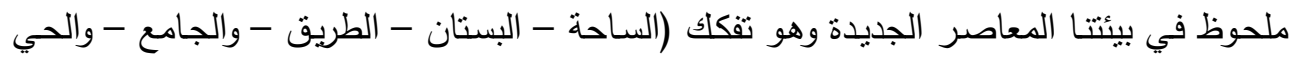

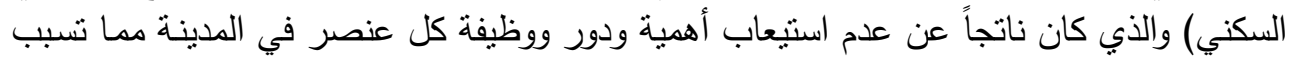

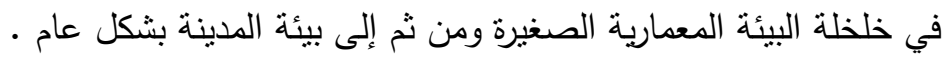

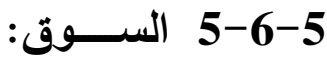

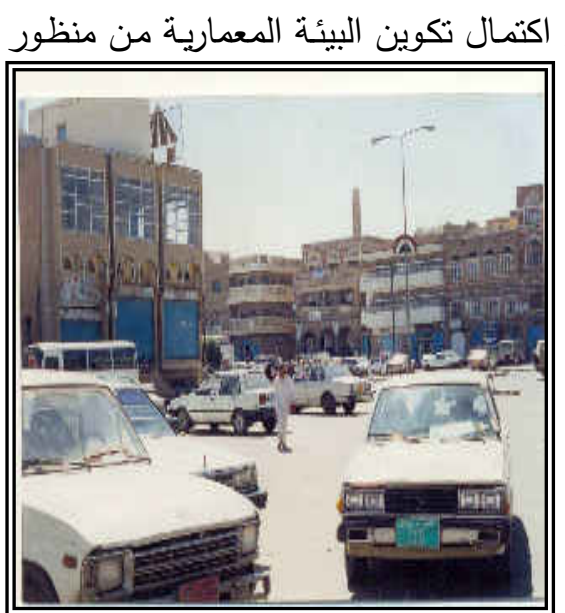

شكل رقم (15) بيئة التجمعات التجارية والأسواق التجارية
يعتبر السوق عنصرا لبيئة المدينـة وبهذا العنصر يكون تكوين المدينة خلافاً إلى العناصر الإنتاجية ، ليثة حيث

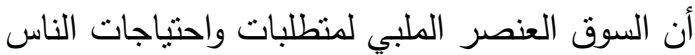
المعيثية ، وإذا ما أخذنا في الاعتبار دوره في تكوين المدينة كونه عنصر أساسي لعملية تكوين المدينة

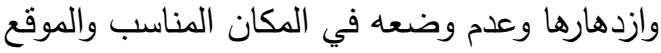

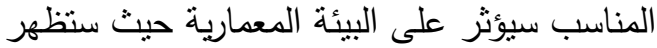
مناطق ازدحام كما هو موجود وحاصل ، فكلما

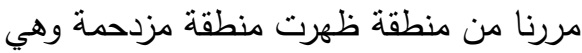

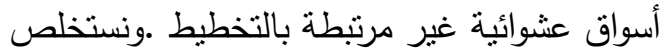

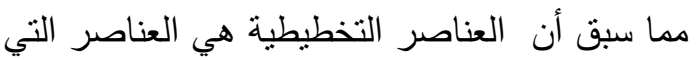
ترتبط باحتياجات الناس وهي مكونات أساسية للبيئة 
المعماريسة والتي تطـورت على اختلاف الطـرق والأسـاليب غيـر أنهـا أخذت طـابع النمطيـة

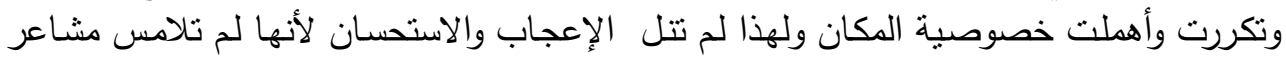

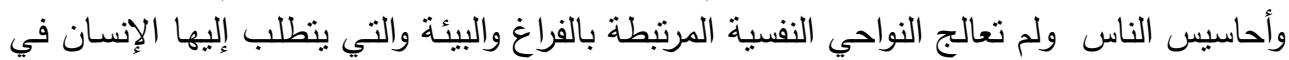

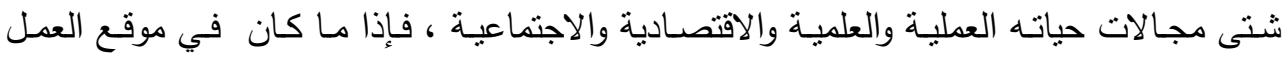

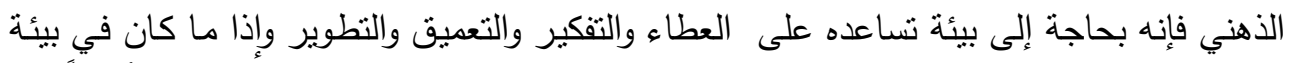

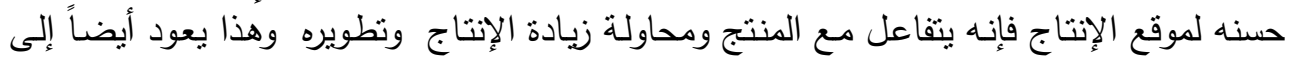
أن البيئة المعمارية والبيئة الصغيرة مرتبطة بحياة الإنسان المعيشية اليومية التي تساعده على قضاء الئهاء

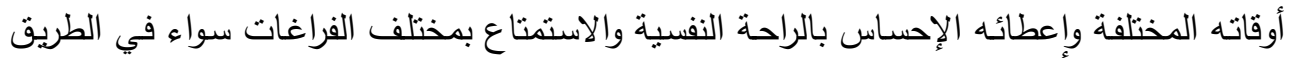
أو السوق - الساحة - الحدائق، كل هذه العناصر ستؤدي إلى التحسن في القدرة الإنتاجية والعطاء.

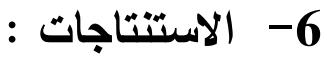

- من خلال الدراسـة والبحث والتحليل لمدينة صنعاء خارج سور المدينة القديمة نجد أن استخلال الفراغ يحدد من خلال سلوكيات المستقيدين وما مدى تفاعلهم معها وفي أوقات مختلفة وبأعداد كبيرة، الأمر الذي سيؤدي إلى زيادة فرص استثمار الفراغ وبالتالي يؤكد ما تم بحثنه ألا وهو

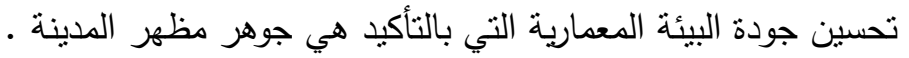

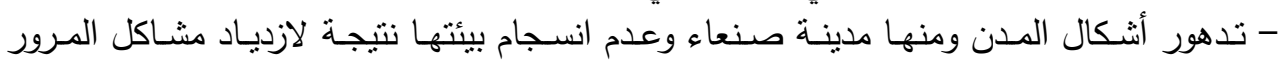

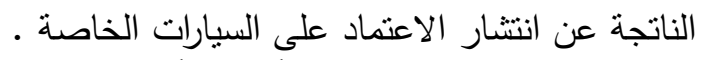

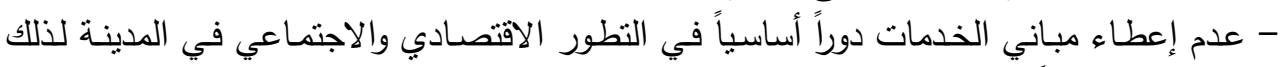

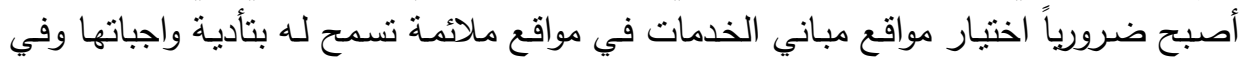

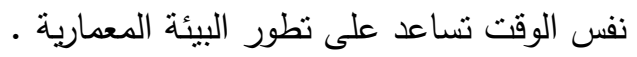

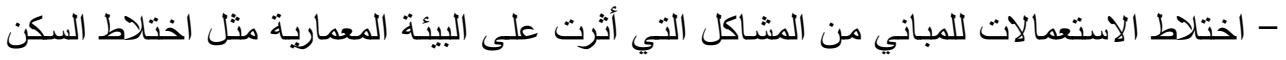

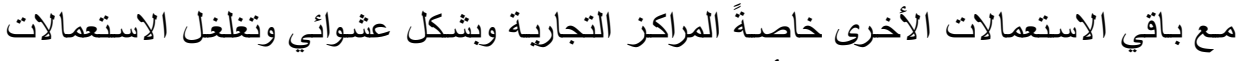
الأخرى بين الأجزاء السكنية حتى أصبحت الوحدات السكنية معزولة عن بعضها البعض البع مها أدى إلى ظهور حالة الققدان للتجانس الاجتماعي وخلق شعور بعدم الانتماء للبيئة المعمارية .

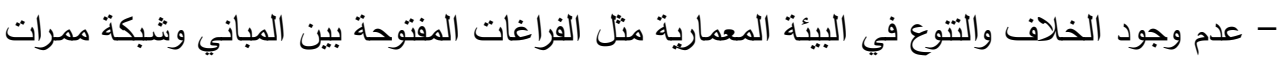
المشـاة ، والاختلاف في المناسيب ، وعدم تطوير البيئات المعماريـة المختلفة ، وعدم اعتبارها

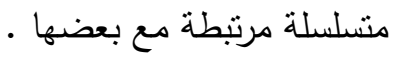

$$
\begin{aligned}
& \text { 7- التوصيات : }
\end{aligned}
$$

- - على المختصين والمهتمين والأكاديميين تقديم مقترحات لتطوير مستوى التخطيط في المدينة.



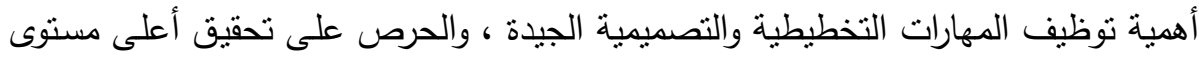

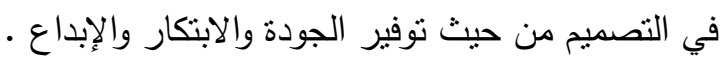

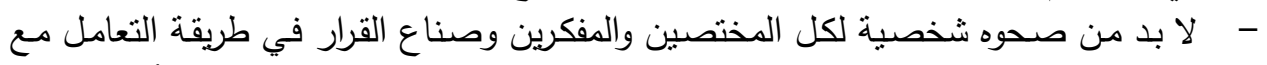
البيئة المعمارية وما يتهددها وذلك للحفاظ على المدينة وبيئتها المعمارية باعتبار أن لنا تراث

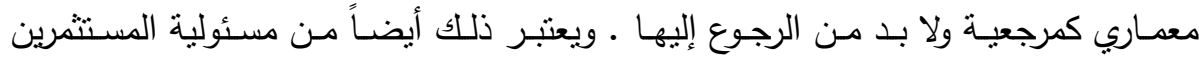

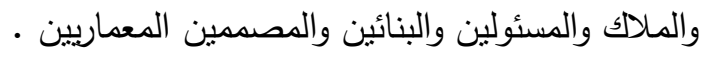




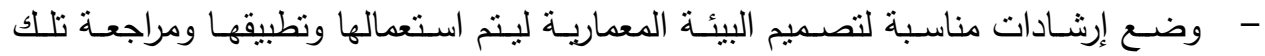
الإرشادات لتتاسب البيئة المعمارية المحلية مع الأخذ في الحسبان الاختلافات في التضاريس

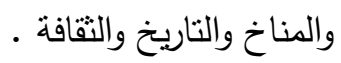
- إعطاء الأمساكن العامـة والثـوارع وممـرات المثـاة والسـاحات العامـة والحدائق وكل الأمـاكن

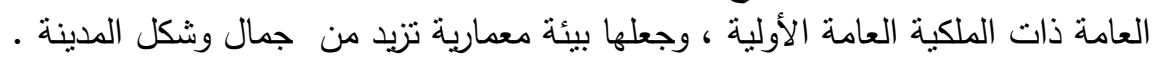

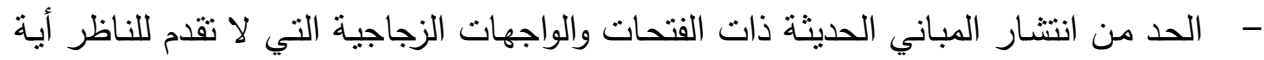

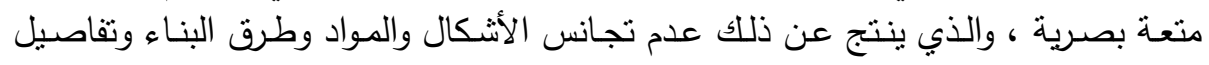

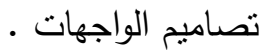
- - إن مواطن هذا العصر في كل مجتمع يتحمل مسؤولية أدبية وخلقية للمحافظة على البيئة

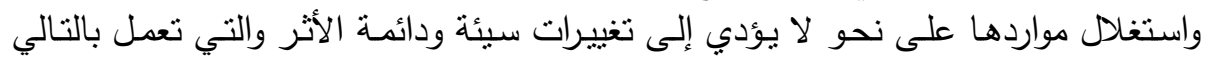

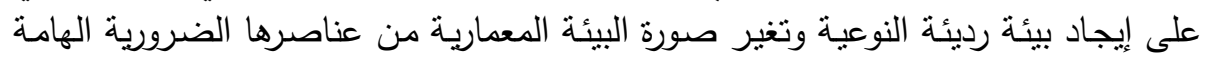

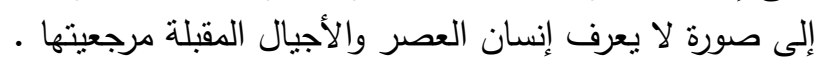

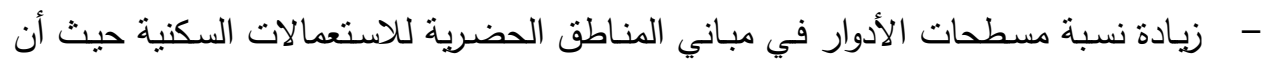

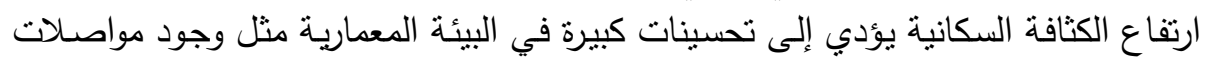

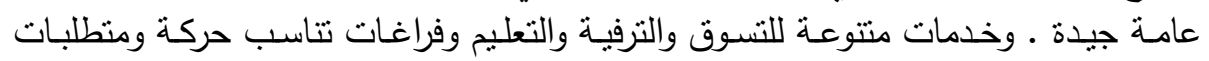

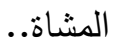

\section{$-0$}

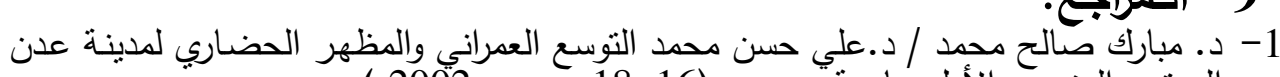

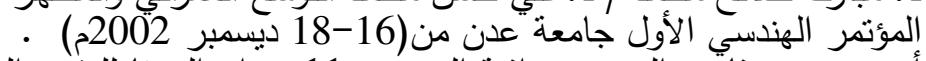

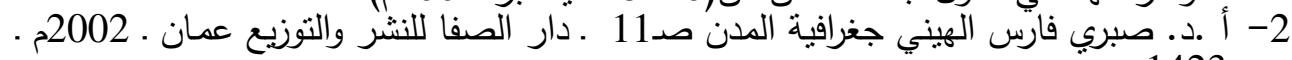
3- أ.د.م 1423هـ. عوف أحمد محمد صدلاح الدين مقدمة في التصميم العمراني (صـ 2002) أكتوبر 17988/

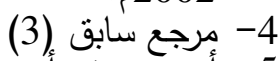

5- أ.د.جم عوف سابق أحمد محمد صلاح الدين مقدمة في التصميم العمراني (صـ 61) أكتوبر 17988/ 2002 6- (د. عبد الباقي إبراهيم) مجلة مركز الدراسات التخطيطية.

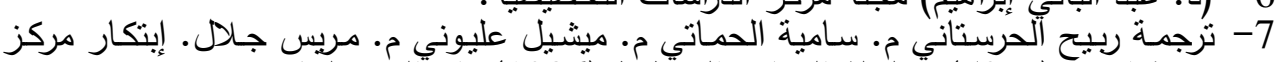

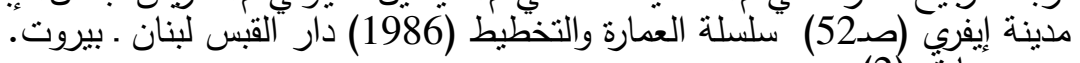

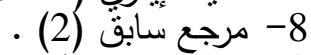

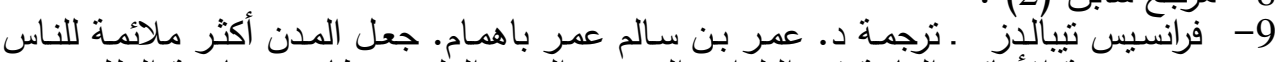

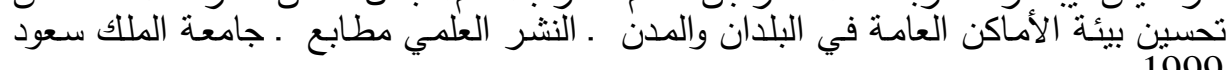
10- كروستوفر دود ـ ترجمة مضر خليل العمر تخطبط المدن والسيطرة على التلوث . صـ 65 ـ .

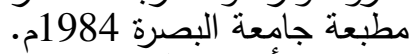

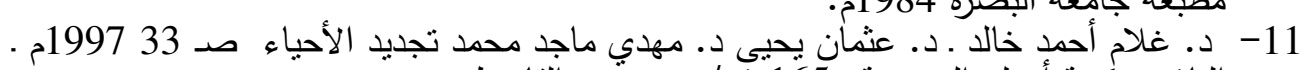

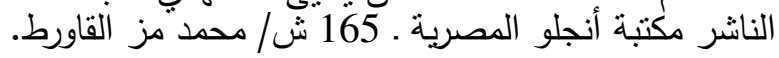

